\title{
The Cognitive Dimension of the Agon between Legal Power and Narrative Meaning
}

Steven L. Winter

Wayne State University

\section{Recommended Citation}

Steven L. Winter, The Cognitive Dimension of the Agon between Legal Power and Narrative Meaning, 87 Mich. L. Rev. 2225 , 2279 (1989)

Available at: https://digitalcommons.wayne.edu/lawfrp/379 


\title{
THE COGNITIVE DIMENSION OF THE $A G O N$ BETWEEN LEGAL POWER AND NARRATIVE MEANING $\dagger$
}

\author{
Steven L. Winter*
}

A judge decides for ten reasons/ nine of which nobody knows ${ }^{1}$

The appearance of the wheels and their construction was as crystal, a single likeness to the four of them, their appearance and construction as if there were a wheel [thrust] inside a wheel. When they moved, they could move to all four sides; they would not turn when they moved. ${ }^{2}$

\section{AN INTRODUctory NARRATIVE, AND A CAUTION}

The relationship between narrative and law is ancient. Robert Cover describes law as a concept rooted in "the sacred narratives of our world." 3 I will be reflecting on the role of narrative in law and, at the same time, using the concept of narrative as a vehicle with which

$\dagger$ ○ 1989 Steven L. Winter.

* Associate Professor, University of Miami School of Law. B.A. 1974, Yeshiva College; J.D. 1977, Columbia University. - Ed. Many of the best ideas in this essay were developed in conversations and correspondence with George Lakoff, Mark Johnson, Mark Turner, Jeremy Paul, Jennifer Jaff, Peter Gabel, and Marc Fajer; each will recognize his or her invaluable contributions. I am also grateful to Lynn Winter, Terry Anderson, Steve Schnably, Michael Fischl, David Caploe, Minnette Massey, Pat Gudridge, and Mark Tushnet for comments on the draft. This article is dedicated to the teachers of my childhood, who told their stories and taught me to experience empathy and to understand that justice is never to be assumed but always to be pursued.

1. W.S. Merwin, Asian Figures 65 (1973) (Chinese proverb).

2. Ezekiel 1:16-17. This is my own translation from the original Hebrew. In the Hebrew, Ezekiel describes the appearance of the wheels as k'aiyn Tarshish - "like the eye of Tarsis." This is a reference to a gem of disputed identity; the translation of this phrase as "crystal" is given by the traditional commentary of Rashi (Rabbi Shlomo ben Yitzchak). I have retained the conventional subjunctive rendering of the "wheel inside a wheel" clause despite the lack of the subjunctive in Hebrew. To capture a sense closer to the original, I have interpolated the bracketed verb. According to Rashi and other traditional Jewish commentaries, the appearance was of two wheels of equal size at perpendiculars - i.e., as if one had been inserted through the other at right angles. This is how the creatures whom Ezekiel was describing could move in all four directions without turning. Id., verse 17.

3. Cover, The Folktales of Justice: Tales of Jurisdiction, 14 CAP. U. L. REv. 179, 180 (1985). Amongst the many debts I owe to Cover's work is for the liberating effect it has had upon my sense of my own past. For a long time, my traditional education in the extensive Jewish canon was abandoned like a piece of old furniture in a musty attic. Cover's work has shown me how the intellectual abundance of these materials can be a profound source of analytic insight. For me, this has been a process of rediscovery - finding, refinishing, polishing, and encountering anew a valuable antique. My use of traditional Jewish literature is, thus, neither pietistic nor imitative. Rather, it is an unorthodox exposition of the deeply human insights of a rich and vital tradition. 
to explore the issues of legitimacy and indeterminacy in law. I begin my inquiry with a narrative, which I shall complete later in this essay and return to subsequently. It is a favorite story from my childhood: a midrash about Abraham as an eight-year-old child. ${ }^{4}$

Terach, Abraham's father, was a maker of idols. Terach left his shop one day, leaving his son in charge. When Terach returned, he found all but one of the idols smashed. The remaining idol was the largest of those in the shop. It stood with a stick tucked under one of its arms. Terach confronted his son about the destruction. Abraham explained that a woman had brought a bowl of flour as an offering to the idols, that the idols quarrelled over the offering, and that the largest of the idols took a stick and destroyed the others. Terach reacted with incredulity and anger: "Why do you make sport of me?" Abraham responded: "Should not your ears listen to what your mouth is saying?"'s

Like Terach's idols, the constancy and certitude formerly associated with the traditional legal tools are today under attack from a variety of iconoclasts. Objectivist logic, analytic rigor, the "plain meaning" of ordinary language, the capacity of precedent and legal rules to determine outcomes; these no longer hold the power once accorded by convention. A new language game has arisen in defense of the tradition: where once stood judicial opinions with their ratio decidendi, statutes with their purposes and "legislative intent," there are now only "texts" and "interpretive communities." 6 Ronald Dworkin compares the development of the law to the writing of a chain novel by the authors of successive generations, determinate legal logic now replaced by the principle of "integrity" and the assumed constraints of the story. ${ }^{7}$ But these are only stopgaps, new idols holding

4. The Midrash is the collection of rabbinic parables that was part of the development of the Oral Law starting in the fifth century B.C. and extending well into the third and fourth centuries A.D. Epstein, Foreword to 1 D.H. Freedman \& M. Simon, The Midrash Rabbah x-xvii (1977). For the midrashic derivation of Abraham's age, see id. at 311-12.

5. Id. at 310-11 (commenting on Genesis 11:28 - "And Haran died "on the face of' his father Terach, in the land of his birth, in Ur of the Chaldees."). See infra note 51 and accompanying text.

6. See, e.g., Fish, Anti-Professionalism, 7 CARDozo L. REv. 645 (1986); Fiss, Objectivity and Interpretation, 34 STAN. L. REV. 739, 744-45 (1982). Fish and Fiss disagree to a significant degree on how they understand "interpretation," see Fish, Fish v. Fiss, 36 STAN. L. REv. 1325 (1984), but they nevertheless share the premise identified in the text.

7. R. DwORKIN, LAw'S EMPIRE 228-38 (1986). Stanley Fish has argued that the analogy to a chain novel does not accomplish the constraints that Dworkin supposes because any subsequent author will be as free as the first to reinterpret the plot, the characters, or the genre. Fish, Working on the Chain Gang: Interpretation in Law and Literature, 60 TEXAS L. REV. 551, 55256 (1982) [hereinafter Chain Gang]; Fish, Wrong Again, 62 TExAS L. REv. 299, 304-08 (1983). I discuss this question infra, text accompanying notes 111-17. 
the axe over the shattered pieces of their predecessors. ${ }^{8}$

There is something surprising in the turn to narrative by modern legal scholars. Indeed, when prestigious law reviews publish symposia reflecting on the comparisons between law and literature ${ }^{9}$ and on the relationships between law and narrative, ${ }^{10}$ one knows that something unusual is afoot. Given the successive developments of refined doctrinalism, policy-oriented professionalism, and sophisticated attention to philosophy that have characterized the American law school since Langdell, some might see a turn to narrative as a step back, a turning aside from "The Law." This turn to narrative might then be explained as a reflection of the "extra-rational" power of narrative, as evocative in the modern age as in more "primitive" times. ${ }^{11}$

But I think that something much more significant is going on. As the academic legal community comes increasingly to doubt its former confidence in the neutrality and objectivity of standard legal analysis, as it retreats from its faith in abstractions, it inevitably seeks solace in the more concrete. I argue that there is something quite important in

8. "The pragmatist reminds us that a new and useful vocabulary is just that, not a sudden unmediated vision of things or texts as they are." R. RORTY, Nineteenth-Century Idealism and Twentieth-Century Textualism, in CONSEQUENCES OF PRAGMATISM 153 (1982); see also id. at 155 ("textualism adds nothing save an extra metaphor to the romanticism of Hegel and the pragmatism of James and Nietzsche").

For discussions exposing the authoritarian or elitist ethics concealed within the interpretive turn, see Bakan, Constitutional Argument: Interpretation and Legitimacy in Canadian Constitutional Thought, 27 OsGoode HALL L.J. 123, 173-76, 188-93 (1989); Brest, Interpretation and Interest, 34 STAN, L. REV. 765 (1982). For a criticism of the "interpretive turn" for failing to acknowledge the inevitable violence of the law, see Cover, Violence and the Word, 95 YALE L.J. 1601, 1601-02 (1986).

9. See Interpretation Symposium, 58 S. CAL. L. REv. 1 (1984); Symposium: Law and Literature, 60 TEXAS L. REv. 373586 (1982); Hirshman, Brontë, Bloom, and Bork: An Essay on the Moral Education of Judges, 137 U. PA. L. REv. 177 (1988). But compare R. PosNeR, LAW AND Literature (1988) with Fish, Don't Know Much About the Middle Ages: Posner on Law and Literature, 97 YALE L.J. 773 (1988).

10. I refer to the current issue of the Michigan Law Review. See also Cover, The Supreme Court, 1982 Term - Foreword: Nomos and Narrative, 97 HARv. L. REv. 4 (1983). Cover's concept of the relationship between narrative and law is discussed infra, at text accompanying notes 104 \& 155-58. I examine Cover's conception of law in greater depth in a recent article, Winter, Transcendental Nonsense, Metaphoric Reasoning, and the Cognitive Stakes for Law, 137 U. PA. L. REv. 1105 (1989) [hereinafter Transcendental Nonsense].

11. For example, the biblical story of the exodus from Egypt has retained its power as a narrative that speaks to the hopes and aspirations of an oppressed people. From Harriet Tubman to Martin Luther King, Jr., the role of the black leader often has been expressed in terms of the biblical story of Moses guiding the Children of Israel out of bondage. Thus, Harriet Tubman who, in the period before the Civil War, helped fellow blacks escape slavery by means of the Underground Railroad was also known as "Grandma Moses." In his final speech before his death in Memphis, Dr. King made a direct allusion to Deuteronomy 34:1-4. "I have been to the mountaintop. ... [A]nd I have seen the promised land. I may not get there with you. But I want you to know tonight, that we as a people will get to the promised land." Speech by Martin Luther King, Jr., Mason Temple, Memphis, Tenn. (Apr. 3, 1968). Cf. Luban, Difference Made Legal: The Court and Dr. King, 87 MICH. L. REV. 2152 (1989) (analyzing King's Letter from a Birmingham Jail). 
this solace-seeking, but that narrative will not save law from its crisis of faith. Rather, the highest use and greatest facility of narrative is as an iconoclastic tool of persuasion to legal and social change. ${ }^{12}$ This conclusion follows from the understanding that, although narrative does play a role in the social construction of meaning, it is not the primary means by which social meaning is institutionalized.

The attraction of narrative is that it corresponds more closely to the manner in which the human mind makes sense of experience than does the conventional, abstracted rhetoric of law. The basic thrust of the cognitive process is to employ imagination to make meaning out of the embodied experience of the human organism in the world. In its prototypical sense as storytelling, narrative, too, proceeds from the ground up. In narrative, we take experience and configure it in a conventional and comprehensible form. This is what gives narrative its communicative power; it is what makes narrative a powerful tool of persuasion and, therefore, a potential transformative device for the disempowered.

On the other hand, narrative is not the primary medium for the kind of institutionalized meaning that is necessary if a prevailing order is to make persuasive its claims of legitimation and justification. Narrative does not meet the threefold demands of generality, unreflexivity, and reliability that are necessary if a prevailing order is credibly to justify itself. The more limited role of narrative in the processes of social construction is as a link between experience and the effective crystallization of social mores. (It is just this prefiguring role that makes narrative a potentially effective transformative device.) But, although narrative may also be employed on behalf of the existing order, this use of narrative as authority is persuasive precisely because it evokes meaning that is already institutionalized. Accordingly, legal narratives of this sort are constrained by preexisting social processes.

I pursue this argument in the following manner: In Part II, I first provide a brief description of what we are learning about the grounded and imaginative nature of the cognitive process. I then elaborate the cognitive structure of the concept narrative and consider the manner in which we employ that concept in recognizing, understanding, and constructing narratives of all types - from folktales like the midrash to avant-garde literature like Waiting for Godot. ${ }^{13}$ In Part III, I em-

12. This, of course, is the modus operandi of Derrick Bell's eloquent work. See, e.g., D. Bell, ANd We ARE Not SAVEd (1987). Feminists have long been aware of the importance and power of the personal narrative; Catharine MacKinnon has called it feminism's "methodological secret." C. MACKInNON, FEMINISM UNMODIFIED: Discourses ON LifE ANd LAW 5 (1987).

13. Beckett, Waiting for Godot, in Seven Plays of The Modern Theater (1962). Godot 
ploy this information about the cognitive and narrative processes to explore the secondary role of narrative in the institutionalization of legal and social meaning. I will identify the cognitive construct that does act as the medium of institutionalized social meaning and discuss its relation to, and constraint upon, legal narrative. This explanation will involve a reconsideration and revisionist account of Karl Llewellyn's concept of "situation-sense." ${ }_{14}$ In Part IV, I describe the cognitive dimension of the process by which narrative functions as a means of persuasion and discuss its use by legal advocates. I close with a brief discussion of how narrative can be a transformative device for the disempowered and those seeking to change the legal and social status quo.

Abraham's literal iconoclasm has always sparked my own. In previous work, I have rejected both the belief that meaning has foundations in objective correspondence with the world and the contrasting view that meaning can be nothing more than the arbitrary result either of social convention or of unconstrained subjectivity. Instead, I have applied the insights of experientialist cognitive theory to describe meaning as located in the process through which the human organism interacts with its world and employs its experience imaginatively to elaborate meaning through the use of experientially grounded imageschemata, models, metaphors, and metonymies. ${ }^{15}$

I will be applying this approach throughout this essay. In contrast

has been called "the play that was to alter the course of theater in the 20th century." Gussow, The Tramps Who Remade the Theater, N.Y. Times, Nov. 6, 1988, § 2, at 1, col. 1. "After 'Godot' plots could be minimal; exposition, expendable; characters, contradictory; settings, unlocalized; and dialogue, unpredictable. Blatant farce could jostle tragedy." Id. at 20, col. 3 (quoting the critic Ruby Cohn).

14. K. Llewellyn, The Common law Tradition: Deciding Appeals 60-61, 122-23 (1960). The ambiguity of Llewellyn's term is legend. See, e.g., W. TwINING, KaRL LlEWELLYN AND THE REALIST MOVEMENT 216-23 (1973) (discussing and evaluating varying interpretations of Llewellyn's conception).

15. Transcendental Nonsense, supra note 10, at 1130-36, 1142-56. It is important to understand that devices such as metaphor and metonymy are cognitive processes and not mere matters of linguistics or rhetoric. Conventional views of metaphor fail entirely to capture its systematicity and centrality in the construction of human conceptual schemes - aspects of metaphor that can be demonstrated empirically. See, e.g., M. JoHNSON, THE BODY IN THE MIND: THE BoDILY BASIS OF MEANING, IMAGINATION, AND REASON (1987); G. LAKOFF, WOMEN, FIRE, AND Dangerous Things: What CATEgories Reveal about THE Mind (1987); G. Lakoff \& M. Johnson, Metaphors We Live By (1980); G. LAKoff \& M. TuRner, More than CoOL. Reason: A Field Guide to Poetic Metaphor (1989); E. SWeEtser, From Etymology to Pragmatics: The Mind-As-Body Metaphor in Semantic Structure and Semantic CHANGE (forthcoming); see also ON METAPHOR (S. Sacks ed. 1979) (particularly the papers of Paul Ricoeur, Max Black, and Nelson Goodman).

In general, conventional theories of semantics are imprisoned by the either/or nature of the subject/object dichotomy. According to the conventional analyses, there is the human subject, the external object, and language which either does or does not connect them: either language maps onto the objective world in a 1:1 correspondence or it does not, in which case it is all arbitrary and socially contingent. I am challenging these assumptions and arguing instead that 
to the objectivist view, I offer a perspective that implicitly rejects the determinacy of analytic logic and affirms the purely constructed quality of narrative understanding. In contrast to the subjectivist view, I question the perspective that narrative is only instrumental and, therefore, at base a purely political tool. I suggest instead that the power and meaning of narrative is simultaneously epistemic and political. This sense of the mutual entailment of the epistemic and the political will yield a threefold set of questions: How is cognitive structure a constraint on meaning? In what sense is power prior to the story? In what way can storytelling be a meaningful constraint on power?

\section{Cognitive Structure ANd NarRative Meaning}

\section{A. Cognition as Imaginative Configuration}

To be human is to seek coherence, constantly to engage in an "effort after meaning." 16 An important part of that process is the superimposition of narrative structure on the raw data of life's events. ${ }^{17}$ The connection between narrative and understanding is reflected in its etymology. The word "narrative" derives not only from the Latin narräre which means "to tell," but also from the Latin gnärus which means "having knowledge or experience."18

It would be a mistake, however, to see narrative as the only or even the primary device by which the mind makes meaning out of the world in flux around it. ${ }^{19}$ To understand and appreciate narrative, it is first necessary to understand the cognitive process that gives rise to the

any sensible approach to language must recognize that it does not come from the world "out there" nor does it come "out of nowhere." See infra notes 55-63 and accompanying text.

Instead, I have described a multidimensional approach to human rationality which recognizes: (1) that we cannot describe the world in any way that is "objective" in the sense of being outside of a particular, human conceptual scheme; (2) that we exist, nevertheless, within a real world which imposes reality constraints on what those conceptual systems can look like; (3) that those constraints are not just "external," but a function of the process by which human rationality is grounded in the imaginative, embodied interaction of the human organism with its environment; (4) that the imaginative dimension of the cognitive process accounts for the relativity of the different cultural elaborations of the world; and (5) that the grounded, embodied nature of human rationality is what makes intersubjective meaning possible.

16. Bruner, Foreword to D. Spence, The Freudian Metaphor: Toward Paradigm CHANGE IN PSYCHOANALYSIS at xii (1987) (attributing phrase to Sir Frederic Bartlett); see also N. Holland, 5 Readers Reading 13-14 (1975).

17. See Cover, supra note 10 , at 5 ("narratives ... are the trajectories plotted upon material reality by our imaginations").

18. OXford LATin Dictionary 768, 1155 (P. Glare ed. 1985). Both of these Latin words come from the Indo-European gnâ ("to know"), which is the root of both the Greek gignoskein and the Latin cognoscere; these in turn yield the English words "know," "cognition," and "noun," amongst others. Turner, Social Dramas and Stories About Them, in ON NARRATIVE 163 (W.J.T. Mitchell ed. 1980).

19. See generally P. Berger \& T. Luckmann, The Social Construction of Reality (1966); N. GOODMAN, WAYS OF WORLDMAKING (1978). 
narrative urge. There is a definite relation between narrāre as "telling" and gnärus as "having experience." It lies in the way the human mind constructs meaning "from the ground up," bootstrapping from its own basic experience in the world and imaginatively elaborating those thought structures or schemata in its further interactions with its physical and social environment. ${ }^{20}$

The human mind employs basic, embodied experiences to construct more elaborate and abstract social meanings. As embodied organisms, we achieve upright posture and balance in the world. We experience our bodies as structured wholes with identifiable parts. We individuate objects outside ourselves. Our visual field appears to have a foreground or center in which objects are in sharpest focus and a periphery, both at the horizon and at the sides, in which things are relatively less clear. We propel ourselves through space to obtain desired objects. Sometimes, our way is blocked by an obstacle and we must exert additional force in order to overcome or avoid it. Some objects are so configured as to contain other objects. Some objects are connected to other objects, even as we link ourselves to others by handholding and other physical means.

Each of these quite basic interactions with the world is generalizable, and each is in fact generalized across a series of other domains. Each of these generalizations is a mental construct by which the human mind creates meaning, a "recurring structure" or "repeatable pattern" that is "a chief means for achieving order in our experience so that we can comprehend and reason about it."21 These basic image-

20. The idea of "cognitive bootstrapping" that I invoke above is related to Lévi-Strauss's notion of bricolage, which he uses to describe the difference between "mythical thought" and modern, "scientific thought." C. LEvi-STraUSS, The SAVAGE Mind 16-22 (1966). As LéviStrauss explains:

The characteristic feature of mythical thought is that it expresses itself by means of a heterogeneous repertoire which, even if extensive, is nevertheless limited. It has to use this repertoire, however, whatever the task at hand because it has nothing else at its disposal. . .

...

... [T] he elements are collected or retained on the principle that "they may always come in handy." Such elements are specialized up to a point . . . but not enough for each of them to have only one definite and determinate use. They each represent a set of actual and possible relations; they are "operators" but they can be used for any operations of the same type.

Id. at 17-18. The difference between the theory described in the text and the concept of bricolage invoked by Lévi-Strauss is twofold. First, Lévi-Strauss was describing and distinguishing mythical or "primitive" thought, on the one hand, from either artistic or scientific thought, on the other. In contrast, experientialist cognitive theory demonstrates that the same processes characterize all human cognition, irrespective of current ideological pretensions either to "scientific rationalism" or to "artistic creativity." Second, Lévi-Strauss assumes that the elements used by the bricoleur are collected haphazardly or at random. Experientialism posits that the most basic of these elements are embodied and that additional elements and constructs are acquired through experience in relatively systematic and predictable ways.

21. M. Johnson, supra note 15 , at 28; $c f$. I. Kant, CritiQue of PuRE Reason A 141, B 180 (N. Smith trans. 1933) ("No image could ever be adequate to the concept of a triangle in 
schemata - like up-down, balance, part-whole, object, center-periphery, source-path-goal, force-barrier, container, and link - are indispensable to human rationality. ${ }^{22}$ They provide structure to human thought, although they are neither objective nor determinate aspects of the world itself. ${ }^{23}$ These schemata are, nevertheless, powerful aspects of human rationality because their operation is automatic and. unreflexive - that is, without conscious awareness, reflection, or control.

The unreflexive use of these schemata to structure our understandings of more complex, abstract domains is everywhere apparent. For example, the use of the balance schema to structure legal reasoning as a process of "weighing" the evidence, "weighing" competing interests, applying multi-part "balancing" tests, and the like all attest to the centrality of our direct embodied experiences to the elaboration and understanding of our abstract intellectual endeavors. Similarly, the source-path-goal schema is the basic structure by means of which we elaborate many diverse concepts metaphorically, as in:

LIFE IS A JOURNEY - One "makes one's way" in life; a successful person is one who "goes far in life"; a person may be unsuccessful because he or she has no "direction." 24

PURPOSES ARE DESTINATIONS, IMPEDIMENTS TO PURPOSES ARE OBSTACLES TO MOTION - What's the "point" of your project? How "far along" is it? The project is growing by "leaps and bounds"; the project has hit a "snag"; it is at an "impasse." 25

ADJUDICATION IS MOVEMENT ALONG A PATH - Litigation is a judicial "proceeding"; the plaintiff must "carry the burden" of proof; a presumption may "shift" the burden of "going forward"; the parties cite supporting "grounds" for their "motions"; alternatively, parties may decide to "forgo" their procedural rights. ${ }^{26}$

These image-schemata and the metaphors they motivate are by no means the only intellectual tools by which we organize our rationality.

general. It would never attain that universality of the concept which renders it valid of all triangles .... The schema of the triangle can exist nowhere but in thought. It is a rule of synthesis of the imagination ....").

22. See Transcendental Nonsense, supra note 10, at 1146-48; Winter, The Metaphor of Standing and the Problem of Self-Governance, 40 STAN. L. REv. 1371, 1384-85, 1493 (1988) [hereinafter Standing]. The balance schema and the force schema each consist of several kindred schemata with related experiential groundings. See M. JoHNSON, supra note 15, at 42-48, 85-89.

23. Transcendental Nonsense, supra note 10, at 1133-34.

24. For other examples, see id. at 1132-33; G. LAKOFF \& M. JoHNSON, supra note 15, at 4144; G. LAKOFF \& M. TURNER, supra note 15, at 4-7, 9-10.

25. See Transcendental Nonsense, supra note 10, at 1132-33; Standing, supra note 22, at 1385; G. LAKOFF \& M. TURNER, supra note 15 , at 4.

26. See Standing, supra note 22, at 1388-91; Transcendental Nonsense, supra note 10, at 1216-19. Because adjudication is a form of purposive activity, this metaphoric conceptualization is actually a special case of the PURPOSES ARE DESTINATIONS metaphor. 
Central to the intellectual process is the construction and sharing within a culture of idealized cognitive models ("ICMs") to structure and make meaningful regular aspects of our daily experience. ${ }^{27}$ These are like "stock stories" or "folk theories" by which humans in a given culture organize the diverse inputs of daily life into meaningful gestalts that relate that which is "relevant" and ignore that which is not.

Suppose, for example, we enter a restaurant, seat ourselves, and are then confronted by a human with pad and pencil. Does this stranger want to hear our life stories? Challenge our right to enter the premises? Take our bet on the afternoon race? Any of these are possible and, on particular occasions, may in fact be the case. Yet, we "know" automatically that the person is asking for our order because we have unreflexively assumed a "restaurant scenario" which organizes our understanding of the events around us. ${ }^{28}$ Although it may vary somewhat from country to country or even region to region, neither the structure nor content of this "restaurant scenario" is arbitrary within a given culture. Thus, although the scenario is socially contingent, it

27. The term "idealized cognitive model" ("ICM") is a term of art in cognitive theory. The concept is described in greater detail in Transcendental Nonsense, supra note 10, at 1152-53.

Richard Delgado provides a particularly thoughtful example of the way in which we commonly reason in terms of idealized cognitive models in his second counter-story "The Anonymous Leaflet." He describes the role that an idealized "model," "mythic figure," or "paragon" plays in faculty hiring decisions. Delgado, Storytelling for Oppositionists and Others: A Plea for Narrative, 87 MICH. L. REV. 2411 (1989). His account corresponds precisely to the kind of reasoning in terms of ICMs detailed by cognitive theory. See, e.g., G. LAKOFF, supra note 15, at $87-88,90 \& 145$.

The concept of an idealized cognitive model is closely related to the idea of a "stock story" used by Gerry López in his excellent article on the role of ordinary cognitive processes in law. López, Lay Lawyering, 32 UCLA L. REv. 1 (1984). Lay Lawyering draws on much of the same social science work as experientialism. Compare id. at $5 \mathrm{nn} .2-4,16 \mathrm{n} .30,17 \mathrm{nn} .36-38$ (referring to the work of Roger Schank \& Robert Abelson, Eleanor Rosch, Amos Tversky, George Lakoff, and Mark Johnson) with G. LAKOFF, supra note 15, at 39-57, 68, 78, 89-90, 271-73 (same). Jay Feinman's recent article on legal classification also draws on the work of Eleanor Rosch; he elaborates a concept he calls a "paradigm" that is substantially close to the ICM. Feinman, The Jurisprudence of Classification, 41 STAN. L. REV. 661, 699-700 (1989). The chief difference is that López and Feinman draw upon the state of the art as of approximately 1980, whereas the approach developed in G. LAKOFF, supra note 15 , and applied in my work is premised on further empirical and theoretical work within those disciplines since that time.

28. See R. Schank \& R. Abelson, Scripts, Plans, Goals, and Understanding: AN INQUIRY INTO HUMAN KNOWLEDGE STRUCTURES 42-46 (1977); Rumelhart \& Ortony, The Representation of Knowledge in Memory, in SCHOOLING AND THE ACQUISITION OF KNOWLEDGE 99 (R. Anderson, R. Spiro \& W. Montague eds. 1977). Schank and Abelson provide an excellent example of how we use the restaurant scenario unreflexively in reading and understanding even a simple literary passage:

Consider, for example, the sentence:

While giving his order to the waiter at Mamma Leone's one evening, Spillane was approached by the owner, a notorious Mafia figure.

The "while"-clause functions to set the Leone's restaurant context with its huge store of generalized and specific world knowledge. Nevertheless, the reader does not slow down to work out who "the waiter" is or how Spillane came to be talking to him, but quickly notes that Spillane is probably at a table, in the act of ordering, in a well-known Italian restaurant.

R. SCHANK \& R. ABELSON, supra, at 37-38. 
nevertheless provides sufficient constraints to ground intersubjective meaning because it is grounded in the particular social experiences of members of that culture.

Not all ICMs consist of scenarios or scripts. Some consist of a related group of propositions grounded in a physical or cultural experience, as in the ICM of mother. ${ }^{29}$ Some are organized by means of image-schemata, as in my description of a cause of action as an ICM structured by means of the source-path-goal schema. ${ }^{30}$ Others are structured in terms of metaphors, as in my description of the ICM of the first amendment as structured in terms of a fluid metaphor (the "free flow" of ideas) and the modern marketplace of ideas metaphor. ${ }^{31}$ Still other ICMs involve metonymies, as is the case with familiar social stereotypes. $^{32}$ But all ICMs share several features in common. Like the image-schemata: (1) ICMs are grounded in or draw upon direct physical or cultural knowledge; (2) they are highly generalized in order to capture and relate together a broad range of particularized fact situations; (3) they are unconscious structures of thought that are invoked automatically and unreflexively to make sense of new information; and (4) they are not determinate, objective characterizations of reality, but rather idealized structures that effectively characterize some but not all of the varied situations that humans confront in their daily interactions with their physical and social environment.

The role and importance of idealized cognitive models in human thought can be illustrated by reconsidering the first part of the midrash about Abraham and the idols with which I opened this essay. This story is only comprehensible because the reader automatically invokes several ICMs to make sense of the events. First, the reader

29. This model is grounded in the social experiences of the nuclear family in a patriarchal culture. It assumes natural childbirth by a married woman who is the primary nurturer and fulltime caretaker. Variants from this model are not prototypical mothers, but rather stepmothers, surrogate mothers, biological mothers, foster mothers, working mothers, or unwed mothers. Minow, The Supreme Court, 1986 Term - Foreword: Justice Engendered, 101 HARV. L. REv. 10, 13-14 (1987) (discussing G. LAKOFF, supra note 15, at 80-81); Standing, supra note 22, at 138586 (discussing G. LAKOFF, supra note 15 , at 74, 79-84).

30. See Standing, supra note 22 , at $1388-90 ;$ cf. supra note 26 and accompanying text.

31. See Transcendental Nonsense, supra note 10, at 1185-92. The fluid metaphor derives from the structural metaphor KNOWLEDGE IS WATER. It yields the rule against prior restraints: The experience of unhealthy, stagnant waters structures the conception of the evil to be avoided as the halting of intellectual progress toward "truth." The market metaphor comes, of course, from Holmes's dissenting opinion in Abrams v. United States, 250 U.S. 616, 630 (1919). It yields the focus on autonomy and on the public forum that characterizes much of modern first amendment doctrine.

32. See G. LAKOFF, supra note 15, at 84-88. What occurs in the case of stereotypes is that attributes which are experienced with respect to some members of a social group are ascribed to all. Stereotypes are metonymies because the experientially grounded part (the attributes of some) comes to stand for the whole (the entire social group). 
automatically combines an ICM of a commercial activity (in which it is understood that it is necessary to have someone to mind the store) with an ICM of filial relations (in which it would be appropriate for a father to ask a son to do so and appropriate for the father to hold the son accountable). Second, the reader makes sense of the moral of the story by invoking and contrasting two opposing ICMs of idol worship. In one ICM, it is understood that idols are thought to have powers and that idol worshipers make offerings to them. In the other, it is understood that idols are totemic human constructions without any actual powers.

The significance of the concept of idealized cognitive models is that it explains the economy of our ordinary thought processes. It took slightly more space to explain the peripheral but indispensable information supplied by these ICMs than to recount the original story. Each ICM is like a crystalline information structure evoked by metonymic terms such as "father," "son," "shop," "idol," and "offering." These individual scripts or "stock stories" are essential subparts unreflexively invoked to make sense of the story. The reader brings these scripts to the story, ready to engage in a joint process of "construction as if there were a wheel [thrust] inside a wheel."

Even the ICMs described above do not exhaust the cognitive processes by which the reader makes meaning out of the midrash. How is it that this artifact of an ancient culture is easily recognizable as a story? How is it that, even without knowing that the purpose of the midrash is to teach a religious lesson, one knows to abstract a moral? ${ }^{33}$ How is it that the reader knows he or she is expected to side with Abraham and not with Terach as the property owner or with the woman as the victim of the social processes of idolatry? The answer, of course, is that we have an ICM for the concept story; this ICM serves as "a cognitive template against which new inputs can be matched and in terms of which they can be comprehended." 34 The internal structure of the ICM is what yields these insights: first, that the story has a moral and, second, that the moral intended by the author can only be obtained by taking Abraham's point of view.

For an account to be perceived as a coherent narrative or story, it must be more than a "simple succession" or "enumeration of events in serial order"; it must be "a configuration." 35 This configuration has a

33. Cf. Cover, supra note 10 , at 5 ("every narrative is insistent in its demand for its prescriptive point, its moral").

34. Rumelhart \& Ortony, supra note 28 , at 131.

35. 1 P. Ricoeur, Time AND NARRATive 65 (1984). I put aside for the moment the philosophical question whether this sequential wholeness is logical or temporal. See id. at 38-40. Ricoeur's approach is to accept as a "transcultural form of necessity" the circularity of the de- 
part-whole structure of a particular type: In Aristotle's famous dictum describing the prerequisites of a proper, complete story, "a thing is a whole if it has a beginning, a middle, and an end." 36 A story is conceptualized as movement along a path, ${ }^{37}$ the sequence of its events configured by means of the source-path-goal schema. ${ }^{38}$ As such, we do not think it much of a "story" if the account "goes nowhere," if it has no "point."39 The role of the source-path-goal schema in elaborating the concept of story structure is related to the PURPOSES ARE DESTINATIONS metaphor. The reader understands the narrator to be asking

pendence between narrativity and our constructed sense of time. Id. at 52-54. Drawing on Heidegger, Ricoeur maintains that both narrativity and the narrative structure of temporality "share the same foundations in within-time-ness." Id. at 64. The account I give employs a similar strategy of seeking escape from circularity in a shared grounding. In this cognitive account, however, both the "logic" of the story and its time-structure are similarly grounded in non-narrative, embodied experience. See infra notes 37-48 and accompanying text.

36. Aristotle, Poetics $50 \mathrm{~b}$.

37. For those who are as devoted to Strunk \& White as I am, it will come as little surprise to find such advice as the following:

[W]ork from a suitable design.... [T] plunge in blindly and start ticking off fact after fact ... lest he miss the forest for the trees and there be no end to his labors. ...

... [E]ven the kind of writing that is essentially adventurous and impetuous will on examination be found to have a secret plan: Columbus didn't just sail, he sailed west, and the new world took shape from this simple, and we now think sensible, design.

....

Many shortcuts are self-defeating; they waste the reader's time instead of conserving it. ... The longest way round is usually the shortest way home, and the one truly reliable shortcut in writing is to choose words that are strong and sure-footed to carry the reader on his way.

W. StrunK, JR. \& E.B. White, The Elements of STYle 70-71, 81 (3d ed. 1979) (emphasis added). The source-path-goal schema appears as well in such philosophically sophisticated work as that of Paul Ricoeur:

To follow a story is to move forward in the midst of contingencies and peripeteia under the guidance of an expectation that finds its fulfillment in the "conclusion" of the story. This conclusion ... gives the story an "end point". . . . To understand the story is to understand how and why the successive episodes led to this conclusion . . . .

1 P. Ricoeur, supra note 35, at 66-67 (emphasis added). See also V. Propr, Morphology of THE FOLKTALE 92 (2d ed. 1968) ("Morphologically, a tale . . . may be termed any development proceeding from villainy . . . or a lack ... through intermediary functions to marriage . . or to other .... [t] ]erminal functions ....") (emphasis added); Cover, supra note 10, at 5 ("narratives ... are the trajectories plotted upon material reality by our imaginations") (emphasis added).

38. Similarly, Lakoff describes the structure of a scenario in terms of these same two schemata:

[T] he scenario is structured by means of the SOURCE-PATH-GOAL schema in the time domain, where

- the initial state $=$ the source

- the final state $=$ the destination

- the events = locations on the path and the path stretches through time. The scenario

is a WHOLE and each of these elements is a PART.

G. LAKOFF, supra note 15 , at 285-86.

39. The Western Apache have a tradition of historical narrative that consists of stories that encode moral lessons of appropriate communal behavior. If a member of the tribe violates such a norm, the story will be told to remind that person how to behave. Typically, the teller is an elder who may tell the story to a larger group without specifying the intended "target." Each story is named after and situated in a place in the local landscape, so that the local geography acts as a metonym for the moral lesson. As described by one Apache: 
him or her to follow the story to its end; the reader, therefore, expects the story to have a point. Because the act of narration is understood as a communicative act, the reader expects that the narrator intends that point as the moral.40

The use of the source-path-goal schema has several other entailments that are central to our understanding of a story as a structured whole. First, the concept of movement along a path towards a goal obviously entails a moving entity, usually a person. This traveller is the protagonist of the story; it is whom the story is about and whom the reader keeps track of. Second, consistent with the conceptualization LIFE IS A JOURNEY, we expect the protagonist to face certain obstacles that must be overcome, usually by force. This provides an agon - a struggle, contest, or dramatic conflict - as the focus of the narrative. ${ }^{41}$ As illustrated in Figure 1, this sketch gives us the most basic story structure: a simple travel scenario.

It is a commonplace in literature that actual journeys provide central thematic structure - as in the biblical story of Jacob's struggle with the angel, ${ }^{42}$ Homer's Odyssey, ${ }^{43}$ virtually the entire canon of Rus-

So someone stalks you and tells a story about what happened long ago. It doesn't matter if other people are around - you're going to know he's aiming that story at you. All of a sudden it hits you! It's like an arrow, they say. . . .

....

It's hard to keep on living right. Many things jump up at you and block your way. But you won't forget that story. You're going to see the place where it happened .... [T]hat place will keep on stalking you like the one who shot you with the story.

Basso, "Stalking with Stories": Names, Places, and Moral Narratives among the Western Apache, in Text, Play, and Story: The Construction AND ReConstruction of SElF aNd SOCIETY 42 (E. Bruner ed. 1984). Note that the Native American narrator of this passage employs the source-path-goal schema, the LIFE IS A JOURNEY metaphor, and a hunting metaphor which is motivated by the structural metaphor RATIONAL ARGUMENT IS WAR. On the latter, see G. LAKOFF \& M. JOHNSON, supra note 15, at 61-65; Standing, supra note 22, at 1410-11.

Milner Ball cites another Native American usage of the LIFE IS A JOURNEY metaphor. In the "Two Row Wampum," the two rows "symbolize two paths or two vessels travelling down the same river together." Ball, Stories of Origin and Constitutional Possibilities, 87 Mich. L. REV. 2280, 2314 (1989).

40. See Grice, Logic and Conversation, in 3 SyntaX AND Semantics: SPEeCh ACTS 41 (P. Cole \& J. Morgan eds. 1975).

41. The centrality of conflict to the practice of storytelling begins with early childhood. At this stage, however, children's stories have very little recognizable structure; they tend to be about conflicts and crises that are beyond their control. See Sutton-Smith, The Origins of Fiction and the Fictions of Origin, in TEXT, PLAY, AND STORY, supra note 39, at 117, 117-23. My account of narrative structure should not, therefore, be understood as an assertion that there is anything universally true or objectively predetermined about the nature of the ICM that I am attempting to reconstruct. Rather, the developed nature of the ICM attests to its cultural construction and social reinforcement. See id. at 123 ("the structure and character of that narrative form is not automatically derivable from some universal childhood experience"). At the same time, the centrality of conflict to even the most embryonic narratives of early childhood corroborates that the cognitive process is a product of the effort to master and make sense of the complexity and adversity of experience.

42. Genesis 32:22-32. For contrasting structuralist and deconstructionist readings of this story, see R. BARTHES, The Struggle with the Angel, in IMAGE-Music-TEXT 125 (1977). 
FIGURE 1

Simple Travel Scenario

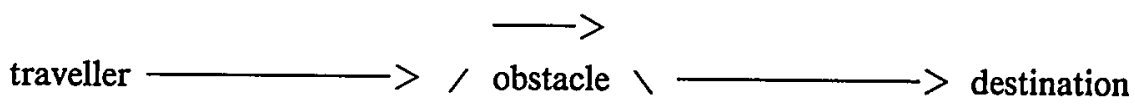

sian folktales, ${ }^{44}$ and even a modern work like Kerouac's On the Road. ${ }^{45}$ In these larger narratives, the part-whole structure is experientially grounded in our knowledge of journeys. This provides a natural starting and ending point in the protagonist's home and a natural beginning and ending for the time dimension of the story. ${ }^{46}$ Typically, the obstacle entailment of the travel scenario is filled out in the story domain as an agon that is an encounter and conflict with an antagonist. Figure 2 provides an illustration of this extended travel scenario.

Not all stories fit so neat and so ready-made a structure as that provided by a journey. Nevertheless, the source-path-goal schema remains central to the ways in which stories are constructed. The third entailment of the schema is that it provides the story's internal conception of time. ${ }^{47}$ This is consistent with our conventional understanding of time, which is structured in terms of two source-path-goal metaphors. ${ }^{48}$ Thus, the time structure of a narrative is not dependent upon any correspondence to the "real world," nor constructed in terms of narrative itself, but grounded in our metaphoric conception of time by means of the source-path-goal schema.

43. Homer, The Odyssey (A. Pope trans. 1942).

44. See V. Propp, supra note 37, at 36-39.

45. J. Kerouac, ON the RoAd (1955).

46. Even Kerouac's On the Road, a novel of ultimate rootlessness, begins and ends in New York. Id. at 5, 252-53. Although the Odyssey doesn't actually begin at home, that earlier, untold portion of the story is inferred by the reader. This is a standard mode of variation from prototypical story-structure. See infra notes 65-68 and accompanying text.

47. See G. LAKOFF, supra note 15, at 285-86 (quoted supra note 38). Stories have an internal time structure, or "story-time," that can be different from the temporal order of the storytelling itself, the "discourse-time." Chatman, What Novels Can Do that Films Can't (and Vice Versa), in ON NARRATIVE, supra note 18 , at 118 .

48. Both of these metaphors conceptualize time in terms of motion. In one, time moves toward us; in the other, time is stationary and we move toward and through it. We use these metaphors separately and together. When used separately, we get expressions like: the hours "fly by"; the time "will come"; the days "ahead"; the weeks "past." When used together, we have such otherwise contradictory statements as: "I'm looking "forward' to midsemester break, which will be all next week and the week 'following." ' G. LAKOFF \& M. JoHNSON, supra note 15 , at $41-44$. 
FIGURE 2

Extended Travel Scenario/Basic Travel Story

initial state

[home/Troy/etc.]

final state

[home]

$$
\text { protagonist } \longrightarrow \text { [antagonist }+ \text { agon }=\text { resolution }] \longrightarrow \text { destination }
$$

SOURCE

PATH

GOAL

In many cases, the elaboration of intelligible beginnings and endings is structured by means of a balance schema. As illustrated in Figure 3, a scenario of this type begins with the description of a status quo by the narrator, an initial state in which life is in harmonious balance. Something disturbs that balance - a need, a lack, a deprivation, or a transformation. The protagonist seeks to restore the balance; there is a conflict and a resolution. The original balanced state is restored or some new balance attained.

initial state

final state

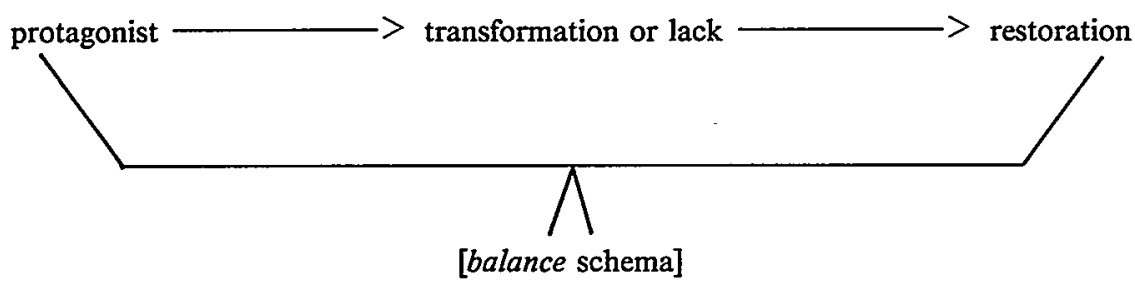

SOURCE

PATH

GOAL

FIGURE 3

Basic Transformation Scenario

The scenarios I have described so far are embryonic narratives, the most elementary story structures. We are now ready to assemble these scenarios into an idealized cognitive model sufficiently rich meaningfully to account for the concept of narrative. Narrative is understood by means of an ICM structured in terms of four schemata: the partwhole, the source-path-goal, the balance, and the force-barrier schemata. These schemata serve as a kind of genetic material or template for a wide variety of different stories in which the plot structure follows a protagonist through an agon to a resolution. As illustrated in 
Figure 4, the simple traveller becomes the more generalizable protagonist. The antagonist is, typically, the agent that causes the imbalance. The protagonist meets the antagonist, and a struggle ensues. This provides an agon as the pivotal point of the narrative. Its resolution also restores the initial state of balance and provides a sense of closure. ${ }^{49}$ The story structure itself allows the reader clearly to infer the motivation of the protagonist.

initial state

final state

protagonist $\longrightarrow$ antagonist $\longrightarrow$ agon $=$ resolution $/$ restoration $/$ reward

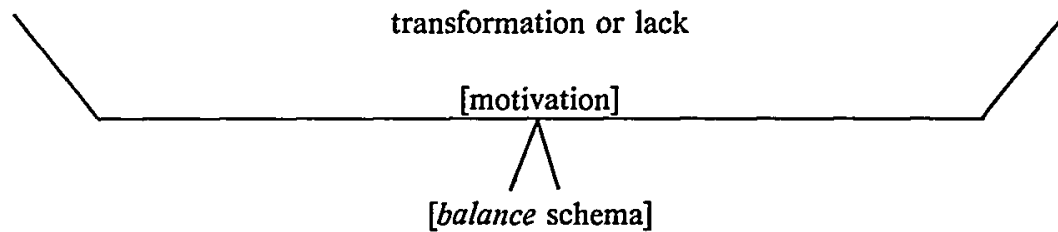

SOURCE

PATH

GOAL

FIGURE 4

ICM of Basic Story Structure

More elaborate stories can be constructed by means of recursive structures in which the protagonist may go through a series of agones until a final resolution or new balance is achieved. These recursive structures take at least two different forms. They can function as modifying subplots that, much as with a relative clause in a sentence, provide information necessary to the progress of the main story. To use an example from Vladímir Propp's extensive study of Russian folktales, the protagonist is often in need of a magic agent like a magic sword or a steed with which to defeat the primary antagonist and redress the initial disequilibrium. The magic agent is usually obtained as a result of a fight or verbal encounter (often involving a strategic deceit by the protagonist) with a character whom Propp designates a "donor." 50 This donor scenario is, thus, an agon within the agon that is

49. Again, a nonprototypical novel like $O$ n the Road provides a useful illustration. The book opens with the line: "I first met Dean not long after my wife and I split up." J. KEROUAC, supra note 45 , at 5 . At the close of the book, the narrator meets quite by accident "the girl with the pure and innocent dear eyes that I had always searched for and for so long." Id. at 250-51. Within two pages, he bids Dean Moriarty good-bye. Id. at 253.

50. V. PropP, supra note 37, at 39-50. Many Native American folktales display exactly the same structural subparts catalogued by Propp. See, e.g., C. LEVI-STRAuSs, Structuralism and 
the larger story.

Alternatively, the recursive structures can operate sequentially, much as a series of conjunctive clauses in a sentence. Both this storystructure and the operation of the general ICM of narrative can be illustrated by completing and analyzing the midrash about Abraham and the idols with which I started this essay. Abraham, it will be remembered, took a stick and smashed all but one of his father's idols. He placed the stick in the hand of the remaining idol and blamed the destruction on that survivor. His father reacted angrily, recognizing the impossibility of his son's story. Abraham responded by pointing out the hypocrisy of his father's position.

"Thereupon," the midrash continues, Terach "seized him and delivered him to Nimrod." Both Terach and Abraham's brother, Haran, were present. King Nimrod challenged Abraham's impudence, and the following argument ensued:

'Let us worship the fire!' he [Nimrod] proposed. 'Let us rather worship water, which extinguishes the fire,' replied he. 'Then let us worship water!' 'Let us rather worship the clouds which bear the water.' 'Then let us worship the clouds!' 'Let us rather worship the winds which disperse the clouds.' 'Then let us worship the wind!' 'Let us rather worship human beings, who withstand the wind.' 'You are just bandying words,' he exclaimed; 'we will worship nought but the fire. Behold, I will cast you into it, and let your God whom you adore come and save you from it.' Now Haran was standing there undecided. If Abram is victorious, [thought he], I will say that I am of Abram's belief, while if Nimrod is victorious, I will say that I am on Nimrod's side. When Abram descended into the fiery furnace and was saved, he [Nimrod] asked him, 'Of whose belief are you?' 'Of Abram's,' he replied. Thereupon he seized him and cast him into the fire; his in[n]ards were scorched and he died in his father's presence. Hence it is written, AND HARAN DIED IN THE PRESENCE OF ('AL PENE) HIS FATHER TERACH. 51

This story is structured as a recursive series of agones in which

Ecology, in A VIEW FROM AFAR 101, 105-08 (1985) (describing variations of a common mythological story amongst tribes in British Columbia).

The overall account of story structure given in the text is very much influenced by Propp and his structuralist successors, particularly Roland Barthes. See Introduction to the Structural Analysis of Narratives, in R. BARTHes, supra note 42, at 79. Although Propp did not identify the basic units in quite the way I have, he recognized the recursive structure of many folkstories. V. PROPP, supra note 37, at 92 ("Each new act of villainy, each new lack creates a move. One tale may have several moves...."). My formulation owes a great deal to conversations with George Lakoff and Mark Turner.

51. 1 D.H. Freedman \& M. Simon, supra note 4, at 311 (quoting Genesis 11:28). The rabbis of the midrash interpreted 'al pene as if the verse read "al yideh. The latter phrase translates literally as "on the hands of" or, more properly, "by the hands of" or "by means of." The intimation is that Terach's trade in idols led to Haran's death. Id. at 311 n.2.

In the traditional Jewish account, Abraham's father left Ur of the Chaldees to go toward Canaan because of this incident. Commentary of Rashi on Genesis 11:31. On the name change from Abram to Abraham, see Genesis 17:5. 
Abraham bests successively more powerful antagonists until he has achieved his primary goal. First, Abraham engages in uneven combat with the helpless idols. Then, he bests his father in argument. This agon is, of course, verbal; but the practice of verbal argument is itself understood in terms of combat through the structural metaphor RATIONAL ARGUMENT IS WAR. ${ }^{52}$ Abraham wins this agon with his father, who then delivers him to the King. Abraham uses his verbal and logical facility to best Nimrod too. So Nimrod subjects Abraham to the test of fire, which he survives as well. From his first encounter with the inert figures, through that with his father, the King, and finally the elements, Abraham remains victorious.

The denouement, however, concerns the death of Abraham's brother. If one assumes only the lesson of faith that the rabbis of the midrash no doubt intended, the death of Haran can be understood to underscore the seriousness of the moral of the story: Faith in God is not a simple question of belief; it is a matter of life or death. In this view, Haran's death and its attendant lesson become the logical stopping place of the story only because that is the way in which the narrators chose to frame it.

There is, no doubt, some truth to this view. But it misses the role of the balance schema in the construction of this meaning. Moreover, it misses the way in which the unreflexive understanding that a story has balance supports alternative meanings as well. Let me demonstrate the role of the balance schema in structuring both the traditional and a revisionist reading of this midrash.

The traditional reading has power because the midrash starts with a picture of the emptiness of idol worship: Abraham assails his father for the vacuousness of his trade in and worship of idols when he lacks any belief in their power. When Haran proclaims his belief in Abraham's faith, we know that this too is hollow. For his false faith, Haran suffers a very specific punishment: "his in[n]ards [a]re scorched" and he becomes as hollow as his opportunistic protestations of belief. This symmetry is reflected in the statement that "Haran died 'al pene" literally, "on the face of" - "his father Terach." The Hebrew word for "face" (panim) is a variant of the word that means "insides" (penim). In this reading, Haran dies because of Terach's inner hollowness.

The midrash, however, contains another balance configuration that suggests another meaning. At the start, Abraham exploits the absence of his father physically to destroy his father's handiwork. When con-

52. G. LAKOFF \& M. JoHNSON, supra note 15, at 61-65; Standing, supra note 22, at 1410-11. 
fronted about this act, Abraham uses his intellectual prowess to mock the authority of his father. He is then taken before a King whose very name means "rebelled against": The word nimrod is formed from the passive of the Hebrew verb mered, which means "to rebel." Confronted with Abraham's facility, Nimrod's authority fares no better than Terach's. By the end of the story, both authority figures have been deposed. At this point, Abraham's moral power - his faith becomes the agent of his brother's destruction. And so we have come full circle: In the absence of any authority, either father or King, Abraham succeeds in the destruction of his father's offspring and a rival for his father's affection. "Hence it is written, and Haran died on the face of his father Terach." In the reading I am suggesting, the reference to Terach's face is to the competition between Abraham and Haran for their father's affection. Here, the face represents an experientially grounded metonymy in which the face stands for the emotions it displays. ${ }^{53}$ In this revisionist reading, the story is not so much a tale of the triumph of Abraham's monotheistic faith as it is a variant of a systematic biblical theme about the rivalry between brothers that starts with the story of Cain and Abel..$^{54}$

In these alternative readings, we have seen how a single schema like the balance schema can nevertheless provide the structure for substantially different readings of the same story. In the section that follows, I will develop the idea that human cognitive processes are systematic but still not determinate. I will discuss the process of extension by which basic story structure is elaborated to create both inventive, nonstandard narratives as well as more prototypical ones. I

53. This metonymy is used in the familiar expression: "When I saw you come in, my face lit up." The use of this metonymy - in which the face is the source of love, blessing, and salvation - appears elsewhere in the Bible. See Numbers 6:25-26 ("May God shine his face upon you and be gracious to you. May God lift his countenance to you and give you peace."); Psalms 80:19 ("God ... shine your face and we shall be saved.").

54. See Genesis 4:1-15. In Nomos and Narrative, Cover traces the systematicity of the sibling rivalry theme in the context of the ascendancy of the younger to the birthright of the elder. Cover, supra note 10, at 19-24. For the attribution of sibling rivalry between Abraham and Haran, see 1 D.H. FreEdMAN \& M. Simon, supra note 4, at 311,312 \& n.l (the rabbis of the midrash assumed that Abraham must have excelled Haran at everything). The connection between Haran's death and Abraham's striving for a monopoly on his father's affection is further corroborated by what follows in the biblical text. Three verses after the report of Haran's death, the Bible reports that Terach left on the trek toward Canaan and that he took Abraham, Abraham's wife, and Haran's orphaned son along. Genesis 11:31. It omits all mention of Terach's third son, Nahor. See id. at 11:26.

Marc Fajer has suggested to me that the two readings of the midrash can be conjoined in a way that supports the more traditional theme of faith. In this view, the theme of sibling rivalry is a symbol for the competition between commitment to faith (Abraham) and expedience (Haran). That competition is resolved when the father sees expedience die and accepts Abraham's commitment. He suggests that this may explain why Nahor, who is presumedly uncommitted, is left behind. 
will explain as well how this systematic process of narrative construction so readily gives rise to a multiplicity of meanings.

\section{B. Nondeterminacy in Elaboration and Interpretation}

There is a powerful and pervasive illogic in much contemporary discourse that equates the lack of objective foundations with the "radically indeterminate." Perhaps nowhere is this more annoyingly mistaken than in the vogue misidentification of the arbitrary with the socially contingent. The mistaken premise of this syllogism is the assumption that the lack of objective foundations means that there are no constraints. ${ }^{55}$ And, far too often, this yields the equally mistaken assumption that any discussion of regularity in or constraint upon meaning is necessarily a reintroduction of foundationalism.

These are not merely academic issues of only epistemological concern. For many, the absence of grounding or foundations is a liberating phenomenon, "a momentary opening for other ways of being and other forms of life." 56 They think they see a plasticity in the constructed nature of our cultural forms that permits dramatic, unconstrained social transformation. For those of us who perceive the injustice of the current social order, this is a seductive vision because it suggests a clear shot at effective social change. But it is mistaken, doomed to failure because it does not understand or take into account the constraints of the cognitive process, dependent upon experience for the raw material of the models by which it constructs the world. Because many (maybe even most) idealized cognitive models are grounded in social experience, these "raw materials" are often themselves cultural constructions shaped by normative social processes. ${ }^{57}$

55. See Transcendental Nonsense, supra note 10, at 1127-30. The pure social coherence view understands internal consistency as the only test of meaning. Accordingly, it understands systems of meaning as chance products of history and tradition. This is the source of the equation of the arbitrary with the socially contingent: If internal consistency is the only constraint on meaning, then any given system must be arbitrary. And, if any given system is arbitrary, then it follows that any given system can be replaced by any other, equally good system of internally consistent meaning.

56. Boyle, Modernist Social Theory: Roberto Unger's Passion (Book Review), 98 HARV. L. REv. 1066, 1081 (1985). But cf. P. FEYERABEND, Notes on Relativism, in FAREWELL to REASON 19 (1987):

Neither [Protagoras] nor Herodotus asserted, as did other sophists and later "relativists," that institutions and laws that are valid in some societies and not valid in others are therefore arbitrary and can be changed at will. It is important to emphasize this point as many critics of relativism seem to take the inference for granted: one can be a relativist and yet defend and enforce laws and institutions. Id. at 44 .

57. This is the case with the ICM of mother, which is grounded in the social experiences of a patriarchal society. See supra note 29 . Moreover, the process of social construction is interactive and multidimensional: The ICM and the language it motivates serve to encode, communicate, and perpetuate the underlying social practices. For excellent articles that recognize the critical 
In this way, our very ability to construct a world is already constrained by the cultural structures in which we are enmeshed.

Cognitive theory recognizes the social contingency of these models and affirms that they are subject to change. But, because these models are socially reproduced at the level of cognition, they are very difficult to change. The point of the experientialist endeavor is to empower such change by bringing both the models and the means of their reproduction to consciousness. Even this is only half the battle, since cognitive success in remolding these models and changing our cultural forms requires alternative grounds in experience. In the final section, I discuss how narrative can be used to communicate these lived experiences to others even in the absence of objective foundations, determinate meanings, or shared, unmediated experiences.

The interpretive experience common to law and literary criticism counsels that single, determinate, objective meanings are unattainable. Nevertheless, our everyday experience consists of meaningful, even if imperfect, intersubjective communication. For reasons I have developed elsewhere, the pure social coherence view of meaning does not adequately account for this fact because it cannot explain how the system of social meaning is held together except by accident. ${ }^{58}$ Accordingly, I have argued that meaning can only adequately be understood as a product of a multidimensional cognitive process that is grounded in our embodied experiences and elaborated imaginatively and nonobjectively by means of metaphor, metonymy, and socially constructed models. 59

To see meaning as grounded in experience is to reject both the kind of determinacy promised by objectivist logic and the kind of arbitrariness assumed by most social coherence theorists. This is the import of the coinage "nondeterminacy." What I intend to convey with this term is a sense that humanly constructed meanings are not determinate, but are nevertheless framed and constrained by the systematic nature of the cognitive processes. For example, it is hard to imagine a human system of moral reasoning that does not involve and, in fact,

implications of the cultural grounding of behavior and experience, see Binder, Beyond Criticism, 55 U. CHI. L. REV. 888, 909 (1988) ("The awful implication is that it is people's very psyches that institutional structures hold together and that it is these psyches that, in turn, hold instrumental culture together."), and Lawrence, The Id, the Ego, and Equal Protection: Reckoning with Unconscious Racism, 39 STAN. L. REV. 317, 322 (1987) ("We do not recognize the ways in which our cultural experience has influenced our beliefs about race or the occasions on which those beliefs affect our actions."). See also Boyle, supra note 56, at 1083 ("The forms of domination ... reappear in [the] workplace and may be even more secure there because they are covered over by the protective veil of familiarity.").

58. Transcendental Nonsense, supra note 10, at 1121-29.

59. Id. at 1129-59. 
depend upon the balance schema. ${ }^{60}$ But it does not follow that there is anything determinate about human conceptions of morality. For the balance schema structures conceptions of moral obligation as disparate as the retributive nostrum "an eye for an eye,"61 its rabbinic interpretation as a requirement of monetary compensation for physical damage, ${ }^{62}$ and the conceptually more extended injunction of the New Testament to "turn the other cheek."63 To put it another way, human conceptualizations of morality are not arbitrary in the sense that they can be just anything. On the other hand, the imaginative, metaphoric nature of these conceptualizations means that they can be many things of a specified, related type.

It follows from this discussion that I do not offer an ICM of basic story structure as a definition of the categorical, necessary, and sufficient conditions of all stories. It is, after all, an idealized cognitive model. As such, it is only a human construction that describes the prototypical story. ${ }^{64}$ To put it another way, the model describes the conditions sufficient for an account to be recognizable as a story. It does not purport to define or delimit the necessary conditions for narratives.

Nevertheless, it does not follow that the elaboration of nonprototypical narratives is unconstrained or that the processes of elaboration are entirely arbitrary. Rather, other narrative forms are understood by reference to and as variants of this idealized story structure. 65 The simplest cases of nondeterminate structural elaborations are the ones in which the narrator modifies the sequence of the elements of the story by, for example, sending the hero off on a journey before the subject of the quest has been identified. ${ }^{66}$ Other familiar

60. See M. Johnson, supra note 15, at 89-95; B. Buchanan, Moral Accounting (1987) (unpublished manuscript on file with author).

61. Exodus 21:24.

62. Babylonian Talmud, Tractate Baba Kamma 83b.

63. Matthew 5:38-39 ("You have heard the saying, An eye for an eye and a tooth for a tooth. But I tell you, you are not to resist an injury: whoever strikes you on the right cheek, turn the other to him as well ....").

64. My use of the term, "prototypical" is technical. I refer to the cognitive phenomenon of prototype effects in which certain category members are psychologically and cognitively more salient than others. This perception of best examples of category membership is a function of fit or coherence with the idealized cognitive model that structures the particular category. Because the ICM does not express a 1:1 correspondence with the experience it organizes (that is, because it is idealized), it will fit some category members much better than others. For further discussions of this phenomenon, see Transcendental Nonsense, supra note 10, at 1136-53, 1157-59; Standing, supra note 22, at 1385-86.

65. Cf. P. RICOEUR, supra note 35, at 69 ("Innovation remains a form of behavior governed by rules. The labor of imagination is not born from nothing. It is bound in one way or another to the tradition's paradigms.").

66. See V. PROPP, supra note 37, at 107. 
examples include the flashback, a device familiar in film narratives but no less common in visual narratives such as painting. ${ }^{67}$ In any of these cases, we can have the agon before the lack or even the denouement before the introduction of the antagonist, etc. ${ }^{68}$ Any of these "disordered" narrative configurations makes sense because the reader can be expected to reconstruct and make sense of the story in terms of the ICM of a prototypical narrative.

Most importantly, the very schematized nature of the ICM creates the possibility of innumerable instantiations. The protagonist can be hero or anti-hero. The antagonist slot need not be filled by an actual villain, but can be instead the object of the protagonist's affection, as in a romance. In this case, the agon is the pursuit and courtship, reflecting a cultural understanding LOVE IS WAR, as in the phrase "the battle between the sexes" or the proverb "all is fair in love and war." 69 Or the protagonist can be an idea, the antagonist another idea or theory, with the rational argument serving as the agon of this "narrative" via the structural metaphor RATIONAL ARGUMENT IS WAR. ${ }^{70}$

To return to more prototypical narratives, the antagonist slot can also be filled by a character trait of the protagonist. In that case, the agon can be the protagonist's struggle with his or her own character flaw, as is common in classical tragedy. In this genre, the balance of the narrative is often obtained by the use of the up-down schema and the symmetry of the protagonist's rise to and fall from power. In other cases, the narrative's agon need not produce a positive resolution but can result instead in a lesson learned by the protagonist. This is frequently the case in moral narratives like Aesop's Fables, where the hero loses the confrontation with self or other but gains an insight worth having.

The possibilities of elaboration are almost endless. Yet, the comprehensibility of each instantiation is maintained by the relative economy of structure that unites these quite varied narratives. Certain

67. See Goodman, Twisted Tales; or, Story, Study, and Symphony, in ON NARRATIVE, supra note 18 , at $99,104-06$.

68. Nabokov's Pale Fire provides an ingeniously constructed narrative in which the narrator, a foreign-born college professor, misreads an entirely unrelated poem as a veiled reference to the story of a deposed Eastern European monarch. The story is presented in fragments as line-byline notes to the text of the poem. V. Nabokov, PaLe FIRE (1962). The reader is thus challenged to reconstruct the story-line much as a detective - or academic - pieces together the disparate pieces of an intellectual puzzle.

69. See G. LAKoff \& M. JoHNSON, supra note 15 , at 49.

70. Thus, for those who are curious, narrative is the subject of this piece with free subjectivity and unconstrained legal power serving as the antagonists. The essay is structured as a recursive series of agones between narrative meaning and subjective power. Hence the title. I leave it to the reader to determine the winner. 
elaborations become conventionalized as recognizable genres: the myth, the folktale, the joke, the romance, the tragedy, the comedy of manners, the novel of ideas, the academic essay. Thus, the category narrative can be understood as a radial category ${ }^{71}$ consisting of a central idealized model that both permits nondeterminate instantiations and supports numerous conventionalized extensions. ${ }^{72}$

Avant-garde narrative is a special kind of variant that requires additional attention because it seems in no way to fit the ICM that I have described. To understand the phenomenon of avant-garde narrative, it is necessary to delve a bit deeper into the construction of prototypical narratives. In tracing the basic ICM of narrative and sketching the means of its structural elaborations, I have only begun to describe the possible complexities. Around the bare bones of this typical structure, the narrator can hang the muscle of the particular plot, the sinew of the connective episodes, the flesh of particular characterizations, the pigment of descriptive or mood-defining passages, and as many layers of conscious and unconscious meaning as the mind inevitably devises.

How is this done? Roland Barthes, for example, provides a microcosmic division of the functional units of narrative into nuclei, catalyzers, indices, and informants. ${ }^{73}$ Nuclei. "constitute real hinge-points of the narrative (or of a fragment of the narrative)." 74 Catalyzers "merely 'fill in' the narrative space separating the hinge functions."75 Informants identify the time and place of the story. ${ }^{76}$ Indices, "a more or less diffuse concept," are atmospheric, characterizational, psychological. 77 For Barthes, the nuclei can be related into a "logical succession" that he calls a "sequence." $78 \mathrm{He}$ gives as an example "the homogeneous group 'Having a drink." "79 Each of these sequences "constitutes a new unit, ready to function as a simple term in another, more extensive sequence." 80

71. The term, "radial category" is a term of art in cognitive theory. See G. LAKofF, supra note 15, at 83-84. I provide more extensive explanations of the concept in Transcendental Nonsense, supra note 10, at 1148-56, and Standing, supra note 22, at 1385-86.

72. Cf. P. Ricoeur, supra note 35 , at 70 ("Rule-governed deformation constitutes the axis around which the various changes of paradigm through application are arranged.").

73. Introduction to the Structural Analysis of Narratives, in R. BARTHEs, supra note 42, at 9293, 96.

74. Id. at 93; see also id. at 98 (these "define[] the very framework of the narrative (expansions can be deleted, nuclei cannot)").

75. Id. at 93 .

76. Id. at 96 .

77. Id. at 92-93.

78. Id. at 101.

79. Id.

80. Id. at 102-03. 
This should sound like the description of the role of ordinary ICMs in the construction of a literary passage that I gave above in connection with the first half of the midrash. It is: Even without an extra-narrative concept like ICM, Barthes has identified the role of the ordinary cultural ICMs in forming the semantic units, if you will, of narrative structure. Paul Ricoeur provides much the same account of the "conceptual networks" that make up one's understanding of a concept like action. ${ }^{81}$ Ricoeur goes on to explain "narrative understanding" as both "presupposing a familiarity with the conceptual networks constitutive of the semantics of the action" and "a familiarity with the rules of composition that govern the diachronic order of a story." 82 Or, in other words, narrative understanding requires general cultural knowledge both of the ICMs of various everyday events and of the ICM of narrative by which they are configured into a coherent composition called a "story." Wheels thrust within wheels, again.

Particular instantiations of narrative have one additional dimension important to our inquiry. There is virtually no limit to the catalyzers that can be introduced between the sequences of a plot or the nuclei of a sequence.

This generalized distortion is what gives the language of narrative its special character. A purely logical phenomenon .... it ceaselessly substitutes meaning for the straightforward copy of the events recounted. On a meeting in "life," it is most unlikely that the invitation to take a seat would not immediately be followed by the act of sitting down; in narrative these two units, contiguous from a mimetic point of view, may be separated by a long series of insertions .... .

... Distended, the functional nuclei furnish intercalating spaces which can be packed out almost infinitely; the interstices can be filled in with a very large number of catalysers. ${ }^{83}$

Thus, not only can individual stories instantiate and reorder the elements of the ICM of narrative in different ways, they can bend, shape, and fill out the subparts of the narrative in diverse ways and to varying degrees.

With this introduction, it should be easy to see how more avantgarde narrative is developed. In Stoppard's Rosencrantz and Guilden-

81. Ricoeur describes these "conceptual networks" as making up the reader's prenarrative understanding of the world. He further explains that the narrator draws upon these preunderstandings - in his terminology, "prefiguration" or "mimesis," (mimesis-sub-one) — in relating them together and composing the story. P. Ricoeur, supra note 35, at 55-56.

82. Id. at 56.

83. Introduction to the Structural Analysis of Narratives, in R. BARTHEs, supra note 42, at 119-20. Barthes goes on to note some constraints inherent in the sequence and the medium. With regard to the latter, he notes: "[W]riting contains possibilities of diaeresis - and so of catalysing - far superior to those of film: a gesture related linguistically can be 'cut up' much more easily than the same gesture [when] visualized . ..." Id. at 120. 
stern Are Dead, ${ }^{84}$ for example, the narrative structure of the play is parasitic on the story-line of Hamlet. It is the latter play which provides the more prototypical protagonist, antagonist, and agon; the narrative of the Stoppard play is an elaborate filling out of the interstices of the plot from the point of view of Rosencrantz and Guildenstern, two of Shakespeare's minor characters. Much of this intercalation consists of extended waiting scenarios, with an extra dollop of ennui and angst about the meaning of it all. Even so, Rosencrantz and Guildenstern's ordeal consists of serial journeys (to Elsinore, to England) for unknown purposes and to unknown ends. Thus, the basic configuration and meaning of the play is a composite of the simple travel scenario and the LIFE IS A JOURNEY metaphor.

To be sure, Rosencrantz and Guildenstern experience their own agones - with the players, the pirates, and more deviously with Hamlet himself. But compared to the more structured agones of Hamlet, theirs seem random and capricious. That, of course, is also part of the intended theme: Because meaning is something that we as humans construct, it is always easier to see order and structure in the lives of others at a distance than it is to be certain of meaning and purpose when confronted first hand with the uncontrollable contingencies of one's own life.

Stoppard's play is, of course, influenced by Samuel Beckett's earlier Waiting for Godot. At first glance, the structure of Godot appears to be even less obviously related to the ICM that I have described. Yet, as Barthes points out, Godot can be understood as "yet another game - this time extreme - with structure." 85 Beckett has simply adopted and extended - in Barthes' terminology, "extensively catalyzed" - a basic waiting scenario. ${ }^{86}$ This is announced quite plainly in the title and throughout the play. ${ }^{87}$ The central meaning of the play lies in the rich entailments of the waiting scenario: Many people live their lives waiting for some external force that will "fix" things or set everything right. Religion - waiting for God or the Messiah - is only one possible instantiation.

Moreover, Beckett employs quite conventional imagery to make his allegory fully comprehensible. The action (such as it is) takes place at the side of a road; Vladimir and Estragon are identified as fellow travellers. ${ }^{88}$ Beckett thus explicitly evokes the travel scenario that is a

84. T. Stoppard, Rosencrantz and Guildenstern ARe Dead (1967).

85. R. BARTHES, supra note 83 , at 120 n.1.

86. Id.

87. See, e.g., Beckett, supra note 13, at 28 ("Time has stopped.").

88. The play begins with the stage direction: "A country road. A tree." Beckett, supra note 
predominant aspect of our conventional understanding of narrative. Moreover, Beckett invokes other conventional metaphoric conceptualizations familiar to the literary tradition in addition to the LIFE IS A JOURNEY metaphor. For example, Beckett identifies the character of Pozzo with the conventional poetic metaphor A LIFETIME IS A DAY and its related metaphor LIFE IS LIGHT. ${ }^{89}$ Thus, in Act I, Pozzo counsels Vladimir and Estragon that "if I had an appointment with a ... Godot ... I'd wait until it was black night before I gave up."90 And, in Act II, Pozzo (now blind) laments: "They give birth astride of a grave, the light gleams an instant, then it's night once more."91

In this way, even nonstandard narratives like Godot are nevertheless comprehensible in terms of the same structural processes and conventional metaphors as more prototypical narratives. Indeed, the strategy of even the most unstructured narrative is to draw upon the reader's natural urge to seek order and meaning; this is the modus operandi of the fully avant-garde work "which, as in Joyce's Ulysses, challenges the reader's capacity to configure what the author seems to take malign delight in defiguring. In such an extreme case, it is the reader, almost abandoned by the work, who carries the burden of emplotment."92 In fact, Joyce explicitly dares us to configure his work as an ordinary travel scenario by giving the book the name of the hero of Homer's Odyssey.

In this way, the category narrative forms a radial category consisting of a central case and related conventionalized extensions. The central case of the category is structured in terms of the idealized cognitive model I have sketched; the extensions are variants of this structure, often configured in conventionalized genres. Even the most

13, at 3. For Beckett, such stage directions are an integral part of the play: "Though his plays are abstract, they are rooted in particular environments - a country road with a single tree, an old man's sparsely furnished den, a mound of earth. Symbolism rises organically from the material." Gussow, Critic's Notebook: Enter Fearless Director, Pursued by Playwright, N.Y. Times, Jan. 3, 1985, at 14, col. 3 (discussing threatened suit by Beckett against a production of Endgame over change in scenery).

The characterization of the two protagonists as fellow travellers is made explicitly at the close of Act I when Estragon says: "I sometimes wonder if we wouldn't have been better off alone, each one for himself. We weren't made for the same road." Beckett, supra note 13, at 44 (stage direction omitted).

89. On the systematicity of these metaphors in literature and everyday expression, see $G$. LAKOFF \& M. TURNER, supra note 15, at 6, 11-12, 27-34. Familiar examples are lines from a Shakespearean Sonnet ("In me thou see'st the twilight of such day/ As after sunset fadeth in the west") (Sonnet 73); Macbeth's soliloquy spoken just before his death ("Out, out, brief candle!") (Macbeth, Act V, sc. v, 1. 23); and Dylan Thomas' poem, Do Not Go Gentle into that Good Night (found in D. Thomas, Collected Poems: 1934-52, at 16 (1952)).

90. Beckett, supra note 13 , at 27.

91. Id. at 77-78.

92. P. Ricoeur, supra note 35 , at 77 ; see also id. at 73 . 
peripheral cases are nevertheless understood in terms of the model from which they depart. In this way, the concept narrative is systematic and structured but nondeterminate in elaboration. "The same concepts, rearranged, exchange, contradict, or invert their values and their functions, until the resources of this new combinatorics are dissipated or simply exhausted." 93

Even so, flexibility of structure is not the primary source of the nondeterminacy of narrative meaning. Rather, it is the ineluctable process of cognitive mediation - what Ricoeur calls "the threefold mimesis"94 - that insures nondeterminacy. At no point in the narrative process is there a 1:1 correspondence between the content of the narrative and a real world referent; at each of the relevant points, the account is constructed, reconstructed, and re-constructed yet again. The narrator does not tell his or her story from the raw, unmediated data of life, but rather assembles and makes use of the preexisting cultural ICMs with which he or she apprehends the world. The narrator then configures these nuclei to form a recognizable story-pattern with an apprehensible meaning. By the time the reader confronts the story, the original experiences and ideas have been twice rendered and shaped by cultural and narrative forms. The reader inevitably transfuses the narrative with his or her own reconstructive effort, ${ }^{95}$ decoding the plot and the message in relation to the ICMs that the reader brings to the process of understanding and interpretation.

In this sense, nondeterminacy of meaning is a by-product of the very process of communication itself. Communication is possible because humans share the experience of embodied interaction with the environment. That interaction produces sub-linguistic structures the image-schemata - which are used to construct sense and meaning. Similarly, those within a culture share an unconscious stock of cultural ICMs that, from an epistemic point of view, are no more than useful cultural theories for organizing and making sense of a complex experience. The very usefulness of these cognitive structures inheres in their schematized, generalizable form; this, in turn, gives rise to nondeterminacy in elaboration and interpretation. Communication is

93. From Mythical Possibility to Social Existence, in C. LEv1-STRAUSS, supra note 50, at 157, 172 (describing the "mysteriously prolific" dynamic of mythic thought).

94. P. Ricoeur, supra note 35 , at 52-87.

95. On the role of reader response theory in literary interpretation, see generally S. FISH, Is There A TEXT IN THIS Class? 13 (1980) (stating the unqualified conclusion that formal units are always a function of the interpretive model one brings to bear (they are not in the text')). See also id. at 14 ("[i]t is interpretive communities, rather than either the text or the reader, that produce meanings."); N. HollaND, supra note 16 (applying insights of psychoanalysis); N. Holland, The BRAIN OF ROBERT Frost (1988) (applying insights of cognitive science). 
possible, but there are no guarantees. The reader may be constrained to interpret a narrative by means of preexisting ICMs, and to do so in a way that conforms to a cultural ICM of story-types. But there is nothing that determines the particular instantiations chosen in the interpretive process. The reader attempts to conjure up the world view of the ICMs invoked by the author and usually succeeds. But the reader remains free to invoke alternative ICMs not intended by or not shared with the author and, therefore, to construct alternative meanings.

We have already seen how the midrash of Abraham and the idols can be read in two very different ways, both of which conform to the text of the story, its indices (like the name "Nimrod" and the biblical referent "on the face of"), and the cognitive constraint of the balance schema. These competing interpretations are each constructed relative to a different ICM that serves as an alternative template for organizing the meaning of the story. The traditional interpretation is made possible by viewing the midrash relative to a paradigm of faith. The revisionist interpretation is rendered by a reading of the same story through the lens of a modern, Freudian paradigm. The traditional reading recreates the world view of the narrators and thus enables the reader to approximate the authors' intended religious lesson. The revisionist reading assumes a different interpretive stance and therefore reconstructs a story of sibling rivalry and Oedipal conflict. From what we know about the rabbinic world view, we can readily conclude that we have obtained a meaning different from the authors' intent. But, from within the modern, psychoanalytic paradigm, we can and do presume that we have reconstructed an unconscious meaning perhaps unknown to, but nevertheless "intended" by the rabbis. ${ }^{96}$

Not all alternative interpretations present themselves as potentially coherent unconscious intentions of the author. A slight divergence of culture between narrator and audience can sometimes make miscommunication inevitable. In Telling the American Story, ${ }^{97}$ Livia Polanyi recounts just such a failure. She was teaching in Amsterdam at the time. Her Dutch colleagues would ask why she had chosen to leave behind friends, family, and country to accept an academic appointment in Holland. She would explain that she had moved because of

96. It is because there is an unconscious, unreflexive dimension to thought that there can be "unintended" meanings that even the author might subsequently affirm. And, it is because this unreflexive level of thought is structured by means of culturally shared ICMs that there appears to be no discontinuity between the reconstruction of an author's "intent" and the "intent" or "purpose" of a social practice. See R. Dworkin, supra note 7, at 53-59.

97. L. Polanyi, Telling the American Story: A Structural and Cultural. ANALYSIS OF CONVERSATIONAL STORYTELLING (1985). 
the job and the opportunities it offered. Inevitably, her Dutch interlocutors would express puzzlement and disbelief. Despite her sincere efforts at explanation, these conversations invariably ended with a sense of distance, distrust, and betrayal.98

Only after several years was Polanyi able to reconstruct the reason for the miscommunication. She had given a truthful explanation that reflected the cultural significance of work and professional ambition to an American. Her Dutch interlocutors, however, interpreted the explanation from a cultural perspective that did not recognize these as proper topics of personal, intimate conversation. Relative to their assumptions about conventional motivations for life choices and proper interpersonal communication, the American explanation that "presented a self which was rational, sensible, businesslike, work-oriented, committed and serious," appeared to the Dutch interlocutors as "cold, calculating, uncaring, work-obsessed, ambitious, and slightly inhuman." 99 They therefore would conclude that the speaker "was rejecting their attempts at intimacy by giving them a story which could not possibly be believed." 100

Because narrative is a process that is constructed relative to such

98. Id. at 4-5.

99. Id. at 5. Some readers have felt that my accounts of cognition both here and in Transcendental Nonsense, supra note 10, focus too heavily on the cognitive processes of the individual to the apparent exclusion of social and cultural forces. But, as discussed supra in text accompanying notes 57-58, the grounding of idealized cognitive models in social experience means that the ICM operates as the internal cognitive agent of social construction. Cf. Binder, supra note 57, at 907 ("It is the embodiment of [selfish instrumentalism] in the structures of everyday life - employment markets, factories, schools, singles bars, supermarkets, bureaucracies - that prevents people from developing any alternative conception of self.").

For example, Polanyi's story nicely illustrates how the individual herself is socially constructed. As an American, the narrator has internalized a self-concept that includes a highly individualistic, particularly American ICM of self that locates one's work, job, or career as central to one's identity. In other cultures, however, differences in child-rearing practices and patterns of social organization provide experiences that ground a very different concept of self. Thus, Alan Roland's psychoanalytic work in India and Japan led him to postulate a "familial self" organized around "emotional connectedness and interdependence . . . where there is a constant affective exchange through permeable outer ego boundaries" and where "the experiential sense of self is of a 'we-self' that is felt to be highly relational in different social contexts." A. Roland, IN SEARCh of SElF in INDia AND JAPAN: Towards a Cross-Cultural PsyCHOLOGY 7,8 (1988). See also Grey, Holmes and Legal Pragmatism, 41 STAN. L. REv. 787, 800 (1989) (For a pragmatist, "the individual person, the knowing, willing subject of Enlightenment epistemology and political philosophy, is only the late and sophisticated product of a complex cultural development."); Rorty, Thugs and Theorists: A Reply to Bernstein, 15 POL. THEORY $564,579 \mathrm{n.28}$ (1987) ("[T] he moral intuitions of the average middle-class member of a modern Western society are contingent, fragile, precious creations, not the expression of something universally human.").

100. L. Polanyi, supra note 97, at 5; cf. A. Roland, supra note 99, at 4 ("[T] intrapsychic self varies significantly if not radically according to the social and cultural patterns of societies .... [P]eople have a different experiential, affective sense of self and relationships, as well as vastly different internalized world views that give profoundly different meanings to everyday experiences and relationships."). 
pregiven understandings, meaning and communication are vulnerable to cross-cultural distortion. Because narrative meaning is an interactive process that requires reconstruction by the reader, reinserting the ICMs of the story's nuclei back into their place in the story-line, it is nondeterminate in interpretation. The process of construction by which a wheel is thrust inside a wheel yields a way of reading that is metaphorically close to Ezekiel's description of his vision, in which the creatures could always face forward and, nevertheless, move in any of the four directions. ${ }^{101}$

\section{NARRATIVe Power AND INSTITUTIONALIzed Social MEANING}

One of the figures of the Jewish communities of Eastern Europe was the magid, an itinerant teller of tales who spoke in the synagogues on the Sabbath. One of these, the Magid of Dubno, was famous for his ability to come up with just the right story or parable on any subject for every occasion. An admirer once asked the magid how he did it: How could he possibly learn and remember so many stories and parables? The magid responded with the following story:

A traveller walking in the forest came across an extraordinary sight. On virtually every tree, there was a target with an arrow dead center. Marvelling at the marksmanship, the traveller followed the trail of bull's-eyes in search of the archer. Eventually, he came across a small boy with a bow and arrow. The traveller asked the boy where he had learned such skillful archery. "Well," the boy explained, "first I shoot at a tree. Then I draw a target around the arrow."

"It's the same with me," said the magid. "First I find out the subject, then I make up a story to fit."102

One naturally assumes that, within the complex of structure and nondeterminacy I have described, the narrator remains entirely free to express any message he or she desires. This common sense notion seems yet more compelling when the narrator is a relatively unaccountable official like a judge, backed up by the power of the State. How can the legal power of the judge be constrained by the concept of narrative? What this question misses, however, is the degree to which the judge, no less than others, is enmeshed in and dependent upon the

101. Ezekiel 1:17, discussed supra note 2.

102. This is the story as I remember it from childhood. Ausubel recounts the story differently: The marksman uses a gun and the targets are chalked onto a courtyard wall. But, more important than these differences in instantiations, Ausubel's version contains a substantive difference. In his version, the magid uses the story to explain that he cannot concoct a story on every subject, but rather collects good stories so that he is prepared for any occasion. N. AUSUBEL, A TREASURY OF JEWISH FOLKLORE 4 (1948). 
structures of social meaning that make communication possible. In this section, I will examine that phenomenon and explore the cognitive role of narrative in law.

\section{A. The "Situation-Sense" of Legal Narrative}

A judge may decide for ten reasons, but the judicial opinion need reveal only one. For those who experience legal doctrine as virtually infinitely manipulable, the doctrinal surface of the judge's opinion merely conceals the subjective purposes, values, beliefs, and biases of the particular judge or the cultural elite from which he is typically drawn. ${ }^{103}$ Still, as a practicing lawyer as well as an academic, I am interested in locating and describing the remaining five unarticulated components of judicial reasoning.

For many of us, the intuition persists that there is something there - some unifying construct or, perhaps, "situation-sense."104 My goal in this section is to explain that intuition, but not to legitimate or justify it. The trajectory of my argument will be to explain what creates the feel of objective justification, to expose it as a social construction, and to locate the role that narrative plays in prefiguring that process. Along the way, I shall be expressing a revisionist understanding of Llewellyn's notion of situation-sense viewed as a descriptive concept rather than a normative ideal.

As discussed in the introduction, the interpretive turn attempts to defend and preserve vague coherence conventions in the face of increasingly devastating attacks on the traditional tools. Although this position has many variants, the basic approach is to understand the Constitution, judicial decisions, statutes, and other sources of legal rules as texts to be read relative to the interpretive practices accepted by a community of interpreters. Ronald Dworkin's version of this position takes the underlying metaphors of LAW AS NARRATIVE and LAW AS LITERATURE and makes them explicit. Law, he suggests, is like a serial novel written by different authors who are constrained to the degree that they accept an obligation to continue the same story.

On the other hand, many see the LAW AS NARRATIVE metaphor as a basis for critique of the legal system. For Robert Cover, an understanding of law and narrative as "inseparably related" is central to an appreciation of the inevitable "polynomia" of legal meanings that dif-

103. I say "he" because the vast majority of our judges, both state and federal, are males and white males at that. For an extended discussion of my divergence from the pure subjectivist and relativist views characterized in the text, see Transcendental Nonsense, supra note 10.

104. K. LlewellyN, supra note 14 , at $60-61,122-23$. 
ferent communities create. ${ }^{105}$ In this view, the defensive invocation of the interpretive turn founders on the problem of justification in the absence of objective, epistemic foundations. There is much to this view: Without a basis for law other than agreement amongst an elite interpretive community, it is difficult to see how legal coercion can be defended as legitimate.

I argue that the LAW AS NARRATIVE metaphor fails either to ground or to account for the operation of the legal system. Those who understand law and other social meanings as grounded only and entirely in narrative face a problem of circularity: How do different members of the group arrive at the same understanding of the metanarrative? The problem with the "everything-is-narrative" account is that it presupposes the very intersubjectivity it is trying to explain. Moreover, both the legitimating and critical views of LAW AS NARRATIVE fail to capture fully the social and operational reality of law. Despite the heterodoxy of our society, the law functions because it "feels" right a good deal of the time; there is a sense in which certain outcomes seem more legitimate than others. If not for that sense, no legal system could survive without the constant exercise of raw, repressive power. ${ }^{106}$ What is necessary for this perception of "legitimacy"?

In Part II, I suggested that both the construction and recognition of narrative depends upon a shared but unreflexive model, a cognitive template against which one unconsciously measures, evaluates, and categorizes new input. It is the culturally shared ICM of narrative that allows one immediately to recognize the novel, the midrash, and the Apache historical narrative as examples of the same "thing," as

105. Cover, supra note 10, at 4-10, 40-44. Sandy Levinson extends the critique yet further and deploys the LAW AS LITERATURE metaphor to argue for the radical indeterminacy of legal meaning. Levinson, Law as Literature, 60 TeXAS L. REV. 373 (1982).

106. See Casebeer, Escape from Liberalism: Fact and Value in Karl Llewellyn, 1977 DukE L.J. 671,693 ("That is, a society governed by a legal system may be stable either because the norms of action are truly shared to a high degree or, momentarily, because the norms are imposed."); see also J. Deutsch, The Reality of Law in America: An Invitation to Dialogue 54-55 (1988) (unpublished manuscript on file with author) ("[W]e are faced with the task of persuading those to whom the law applies, of arguing that what the court or regulator has done is valid. At this point the question becomes one of communicating what will be accepted as truth, and that truth must be capable of being stated ... . in language that is persuasive of a substantive reality."); Binder, On Critical Legal Studies as Guerilla Warfare, 76 GEo. L.J. 1, 5 (1987) ("Legal doctrine ... perpetuates injustice ... by helping to maintain allegiance toward the society as a whole. It does this . . . by invoking and honoring values widely, and falsely, attributed to that society."); Minow, supra note 29, at 67 ("a conception of reality, when it triumphs, convinces even those injured by it of its actuality").

For a thoughtful examination that criticizes prevailing assumptions about the relationship between legal norms and cultural belief in the production of law-abiding behavior, see Hyde, The Concept of Legitimation in the Sociology of Law, 1983 WIS. L. REV. 379. 
instantiations of the same process. ${ }^{107}$ Moreover, I argued that the meaning of any particular story is only possible because it is constructed of pregiven understandings of common events and concepts, configured into the particular pattern of story-meaning.

The success of communication is dependent on these pregiven understandings. When the narrator and his or her audience share a set of cultural ICMs, intersubjective communication proceeds as if unproblematic. This is our experience of everyday conversation with family, friends, and colleagues. When the reader understands a story relative to an alternative ICM, however, it is entirely possible for him or her to interpret its meaning in a manner never contemplated by the author. This is the familiar case in literary criticism; but it is equally familiar as the means by which creative lawyers and judges read precedent. ${ }^{108}$ When the narrator and the audience are attempting to communicate across cultural conventions, misunderstandings will be frequent if not inevitable.

For a legal rule to function as "Law" in the absence of objective foundations, categorical imperatives, or privileged access to the Framers' intent, the subjects of the rule must perceive it as "just the way it should be."109 This occurs when the law is reflective of and structured

107. For a brief discussion of Apache historical narrative and its relation to the ICM of narrative, see supra note 39.

108. Compare, for example, Justice Brennan's account of the history of habeas corpus in his majority opinion in Fay v. Noia, 372 U.S. 391, $411-26$ (1963), with that of the majority of commentators. See Mayers, The Habeas Corpus Act of 1867: The Supreme Court as Legal Historian, 33 U. ChI. L. Rev. 31, 58 (1965); Oaks, Legal History in the High Court - Habeas Corpus, 64 MrCH. L. REV. 451 (1966); see also Friendly, Is Innocence Irrelevant? Collateral Attack on Criminal Judgments, 38 U. CHI. L. REv. 142, 170-71 (1970); Developments in the Law - Federal Habeas Corpus, 83 HARv. L. REV. 1038, 1045-50 (1970). Nevertheless, Justice Brennan's version remains both plausible and persuasive because it is reconceptualized relative to a modern notion of due process. Characterized as "a prompt and efficacious remedy for whatever society deems to be intolerable restraints," Fay, 372 U.S. at 401-02, it follows that "changed conceptions of the kind of criminal proceedings so fundamentally defective as to make imprisonment pursuant to them constitutionally intolerable [do] not . . . obscure the basic continuity of the conception of the writ as the remedy for such imprisonments." 372 U.S. at 414.

Another example of the reconceptualization of legal history in terms of a modern constitu. tional paradigm is the argument made by Herbert Wechsler (and accepted by the Court) in New York Times Co. v. Sullivan, 376 U.S. 254 (1964), that the challenge to the constitutionality of the Alien and Sedition Acts "has carried the day in the court of history." 376 U.S. at 276. For an alternative explanation of the Alien and Sedition Acts that locates these statutes in the mainstream of first amendment history, see Transcendental Nonsense, supra note 10, at 1186-92.

109. Llewellyn discussed much the same idea in his diagnosis of what it might mean to talk about "legal certainty":

And the certainty in question is the certainty after the event which makes ordinary men and lawyers recognize as soon as they see the result that however hard it has been to reach, it is the right result. Then men feel that it has therefore really been close to inevitable. Even most losers, as the strife subsides, may be hoped to look back with something of such understanding.

K. LLEWELLYN, supra note 14, at 185-86 (footnote omitted); accord Llewellyn, The Case Law System in America, 88 Colum. L. REv. 989, 1013 (1988) (P. Gewirtz ed., M. Ansaldi trans.) 
by the same idealized cognitive models that are used in the culture generally. Thus, the social assent commanded by the legal enforceability of a bargained-for exchange is not a mere creature of the imposition of technical doctrines of consideration. Rather, it is a nondeterminate product of the balance schema and of its centrality in establishing a sense of closure and in structuring our understanding of appropriate moral behavior. ${ }^{110}$

With this preface, we can understand why narrative is insufficient as a medium for the kind of institutionalized meaning that is necessary if a prevailing order is to make persuasive its claims of legitimation and justification. The process of legal legitimation that I have described requires three conditions for its success. First, for law to cover the wide variety of fact situations to which it is to be applied, it must be easily generalizable. Second, for law to appear as legitimate in the absence of objective justification, it must evoke the kind of automatic sense of validity - should we call it a "natural law response"? - that is only provided by automatic, unreflexive cultural knowledge. ${ }^{111}$

(excerpts from K. LLEWLLYN, PRÄJUDIZIENRECHT UND RECHTSPRECHUNG IN AMERIKA (1933), translated into English as K. Llewellyn, The CASe LAW System in AMERICA (forthcoming)):

Legal rules provide certainty in the affairs of people whose interests are affected by the law if, in a lawsuit, they yield a result that accords with their real-life norms. Thus, the most important legal certainty for those whose interests the law affects depends on whether the judge can make the direction and degree of semantic change in a legal rule (or a verbal symbol used by the rule) keep up with the corresponding change in the real-life situation. But if the change sanctioned by the judge keeps up more or less, but not quite, then one speaks of the law's mild conservatism. If the change on the judge's part is not noticeably keeping up, then one speaks of crisis in decisionmaking. And, finally, if the change on the judge's part is keeping up perfectly, neither judge nor layman realizes that any change has occurred ....

110. See supra text accompanying notes $60-63$; $c f$. P.S. ATIYAH, PROMises, Morals AND LAw 173-74 (1981) (footnote omitted):

[T] he traditional explanation of an implied promise assumes that the explicit promise is the paradigm case. The implied promise is then treated as a case where no explicit promise is made in so many words, but where, from his words and conduct, it is plain that the party intends to bind himself. ... But there are difficulties with this traditional explanation. What of the person who does not intend to pay ... for the meal supplied to him in the restaurant?

However, although it may well be true that a person who ... orders a meal in a restaurant, creates an expectation that he will pay an appropriate charge, and may, in that sense, be taken to have made a promise . . . . it seems quite plausible to suggest that .... [i]t is because he is bound by an obligation that we feel impelled to imply a promise. ... [T]he source of the obligation ... must be sought elsewhere. ... [I]t is often, perhaps always, the case that the conduct itself justifies the creation of the obligation. A person orders a meal in a restaurant and the meal is laid before him, and he eats it. Surely these facts alone suffice to create an obligation to pay.

111. See Lawrence, supra note 57, at 323 ("Because these beliefs are so much a part of the culture, they are not experienced as explicit lessons. Instead, they seem part of the individual's rational orderings of her perception of the world."); $c f$. R. SCHAFER, ASPECTS OF INTERNALIZATION 109 (1968) ("The term reflective self representation refers to the implicit or explicit notation accompanying realistic thought that it is thought ... and not concrete reality. When the subject suspends his reflective self representations, he disappears as thinker and experiences his thoughts as though they were concrete realities."); P. BERGER \& T. LUCKMANN, supra note 19, at 21 ("The reality of everyday life appears already objectified .... The language used in every- 
Third, for law to function effectively and equitably, it must be communicated with as high a degree of relative reliability as possible.

Narrative cannot fulfill these conditions of generality, unreflexivity, and reliability in communication. First, narrative cannot structure a category or a model. Because narrative comes with its instantiations already in place, it can (at best) provide an example with which to motivate a model. Second, the concrete, specific particulars of any narrative require conscious mediation in the process of analogy necessary for extension to other cases. Third, at the interpretive level, narrative engages the reader in a reconstruction that risks too great an indeterminacy. The number of ICMs required to make sense of the varied parts of a story (not to mention the larger paradigms relative to which one may reinterpret a story entirely) leaves far too much room for misreading the author's intent. Like Ezekiel's creatures, the peril presented by narrative is that it will keep its face to us, but retain its power to move off in any direction without warning.

This is the problem with Dworkin's analogy that compares law to the writing of a serial novel, the chapters held together by a commitment to the principle of "integrity."112 As Stanley Fish has argued, the authors of the subsequent chapters will be free to reinterpret the plot, the characters, or the genre in ways that drastically change the enterprise. ${ }^{113}$ For Dworkin's serial novel is bound together only by the notion that the subsequent authors are committed to making the novel "the best it can be."114 But as Dworkin himself recognizes, the conceptualization of "best" is itself relative to interpretive strategies and commitments. ${ }^{115}$ The story will, therefore, always be subject to radical reinterpretation and reconstruction in light of other ways of being in the world - unless it has its own essence, its own fundamental quality. Dworkin, however, explicitly rejects such objectivist as-

day life continuously provides me with the necessary objectifications and posits the order within which these make sense and within which everyday life has meaning for me.").

In a forthcoming essay, I describe this unreflexivity as a "simple state of transparency" that can be overcome through the technique of "situation self-consciousness." Winter, Bull Durham and the Uses of Theory 53-58 (unpublished manuscript on file with author).

112. R. DworkIN, supra note 7 , at 225-32.

113. Fish makes the strong assertion that any subsequent author will be exactly as free as the first in exercising this capacity for choice. Chain Gang, supra note 7, at 555. One needn't go as far as Fish, however, in order to demonstrate the inadequacy of the chain novel analogy. I provide a weaker version of Fish's critique in the text that follows. In the final section, I explain why I do not accept Fish's strong version of the critique. See infra note 170. For an extended critique of the crypto-objectivist, all-or-nothing character of Fish's position, see my forthcoming Bull Durham, supra note 111.

114. R. DwORKIN, supra note 7, at 229.

115. Id. at 53, 234-35. 
sumptions. ${ }^{116} \mathrm{He}$ asserts instead that, as the story proceeds, the very accretion of detail progressively constrains subsequent authors because they must account for the data within their own interpretive conceptions of what a coherent story can be. ${ }^{117}$

While this position has some intuitive appeal, we have seen already that it is incorrect. The accretion of detail does not foreclose other interpretive understandings even within a single interpretive conception like the ICM of narrative. Because the ICM is sufficiently generalized to allow many instantiations, and because it is nondeterminate in elaboration, the details of a given story can be reordered in terms of many other points of view. Thus, Stoppard has no difficulty turning the story-line of Hamlet into an existentialist meditation on the meaninglessness of life simply by changing the point of view from that of Hamlet to that of Rosencrantz and Guildenstern. ${ }^{118}$ Similarly, there was little difficulty in taking a completed story like the midrash about Abraham and the idols and reinterpreting it in light of a Freudian paradigm. Both the traditional version and my revisionist reinterpretation effectively account for the vast majority of the details, including the hidden elements like the indices. Which makes the midrash the best that it can be?

It is for this reason that the concept of narrative cannot explain the perception of appropriateness that partially sustains the legal process. Only a mental structure like an idealized cognitive model will meet the threefold requirements of generality, unreflexivity, and reliability in communication that are necessary to the operation of law. An ICM is highly schematized, entirely unreflexive, widely shared, and regularly applied. Its unconscious application produces prototype effects: regularized, core instantiations about which there will be little or no conflict within the culture. ${ }^{19}$ Thus, we can depend upon a meaningful

116. Dworkin, My Reply to Stanley Fish (and Walter Benn Michaels): Please Don't Talk About Objectivity Any More, in The Politics of InTERPRETAtion 287 (W.J.T. Mitchell ed. 1980).

117. R. Dworkin, supra note 7, at 234-35. Dworkin suggests that the character of Scrooge in Dickens's $A$ Christmas Carol is subject to many more interpretations at the beginning of the story than he is after the dream sequence and repentance. Id. at 232-34. He acknowledges that there is nothing objectivist about this alleged constraint, but rather that it is a function of "the interpreter's aesthetic convictions .... as much matters of judgment and conviction as" any other interpretive choice. Id. at 234-35.

118. The English playwright Alan Ayckbourn has perfected the device of perspectival shift into a high art. In his play, The Norman Conquests (1975), the events amongst an extended family spending the weekend together in the parent's home is told through three performances over three nights. Each night's performance covers the same time period and the same overall events, but takes place in a different room of the house. By the third performance, the meaning of the events viewed on the first night appears entirely different.

119. On the general phenomenon of prototype effects, see supra note 64 . On the phenomenon of prototype effects in law, see H.L.A. HART, THE CONCEPT OF LAW 123 (1961): 
degree of reliability in communication because of the culturally shared nature of these cognitive models and their grounding in common experience. The experientialist concept of an ICM is, thus, the very model of the kind of culturally self-justifying notion with which the law might operate.

Llewellyn's concept of situation-sense is just such an attempt to normalize legal decisionmaking in the vacuum that followed in the wake of the legal realist attack on formalism. The primary thrust of Llewellyn's conception is to account for and evaluate legal decisionmaking with something more than a subjectivist standard of "measurement by whether I the sparrow, with my bow and arrow, like the specific outcome for a target": 120

For the standard of wisdom to which appeal is being made ... is not any person's personal standard; it is rather a standard which aims to get idiosyncratic preferences largely hewn off until the standard becomes what the courts also are reaching for: something which can be hoped, on thought, to look reasonable to any thinking man; something that can even be hoped to look reasonable in light of that uncommon sense, horse sense. ${ }^{121}$

Even though Llewellyn offered situation-sense as a normative ideal, he denied any claim to objectivism: "[I]t is quite independent, I repeat, of any philosophy as to the proper sources of 'Right Reason' which may be held by any 'Natural Law' philosopher. . . . It answers instead to current life, and it answers to the craft."122

Despite these qualifications, Llewellyn's concept of situation-sense has been almost universally criticized. The primary ground of criticism is that the concept does not acknowledge or leave room for the

There will indeed be plain cases constantly recurring in similar contexts to which general expressions are clearly applicable. ... The plain case, where the general terms seem to need no interpretation and where the recognition of instances seems unproblematic or automatic," are only the familiar ones, constantly recurring in similar contexts, where there is general agreement ....

But compare Hart, The Separation of Law and Morals, 71 HARV. L. REV. 593, 610-11 (1958). I discuss both the congruence of Hart's linguistic theory with experientialism and my critique of his positivism in Transcendental Nonsense, supra note 10, at 1172-80.

Dworkin's notion of a moral obligation to make something "the best it can be" is really only a dressed-up version of the cognitive phenomenon of prototype effects. Something is only "best" relative to an idealized model of what we think it should be. With this Dworkin agrees. See supra text accompanying note 115 . The instinct to read a text in a manner that puts it in its best light is, then, not an essentially moral commitment to authorial integrity. Rather, it is part of the basic cognitive impulse to configure new input in a manner that makes sense: to make it into a coherent whole, a "best example" of an existing ICM or reigning paradigm. Cf. Fish, Dennis Martinez and the Uses of Theory, 96 YALE L.J. 1773, 1793 (1987) (describing Dworkins injunction as "the verbal equivalent of a pat on the back").

120. K. LLEWELLYN, supra note 14, at 276.

121. Id. at 277. By "horse sense," Llewellyn meant "the balanced shrewdness of the expert in the art." Id. at 121 .

122. Id. at 422-23. 
inevitably subjective nature of judging. ${ }^{123}$ This criticism is echoed today by those associated with Critical Legal Studies, who trace their lineage to Llewellyn but reject his formulation as a mistaken objectivist bypass. ${ }^{124}$ Situation-sense was also criticized as internally inconsistent. ${ }^{125}$ " $[\mathrm{T}]$ his vague, subjective principle is the keystone of a system which is the antithesis of the subjective . . ."126 Perhaps the most telling objection to the concept of situation-sense is that no one really understood it. As one commentator put it, "situation sense may be a Janus-faced concept."127 Its very novelty contributed to its obscurity: "Grasp of the concept itself is made difficult by the fact that it bears no marked resemblance to any previously offered guide . . . ."128

Nevertheless, Llewellyn's concept of situation-sense is remarkable in its descriptive adequacy. For, although it lacks the formalized coherence of the experientialist construct of an idealized cognitive model, situation-sense offers far more than the mere focus on context it has sometimes been understood to recommend. ${ }^{129}$ Rather, in Llewellyn's formulation, situation-sense encompasses precisely the qualities of unreflexivity, cultural commonality, and experientially grounded reason that cognitive theory attributes to the ICM.

Indeed, Llewellyn's notion of situation-sense incorporates virtually all of the essential attributes of the idealized cognitive model identified

123. See, e.g., Clark \& Trubek, The Creative Role of the Judge: Restraint and Freedom in the Common Law Tradition, 71 YALE L.J. 255 (1961).

124. See, e.g., Fischl, Some Realism About Critical Legal Studies, 41 U. MIAMI L. Rev. 505, 520 (1987) ("To overstate the matter somewhat, the Realists [like Llewellyn] sought to substitute one form of science for another."); Peller, The Metaphysics of American Law, 73 CALIF. L. REV. 1152, 1240-50 (1985); Feinman, Promissory Estoppel and Judicial Method, 97 HARV. L. REV. 678, 704 (1984) (referring to the "quasi-empirical — and therefore determinate - activity prescribed by the method of situation-sense").

125. See Rohan, The Common Law Tradition: Situation Sense, Subjectivism or "Just-Result Jurisprudence"?, 32 FORDHAM L. REV. 51, 63-64 (1963); see also Feinman, supra note 124, at 704-05 (arguing that, in determining the "type-situation," the level of categorization can always be varied to yield any desired result). For a related discussion of legal argument as a process of frame-shifting, see Jaff, Frame-Shifting: An Empowering Methodology for Teaching, 36 J. LEGAL EDuc. 249 (1986).

126. Clark \& Trubek, supra note 123 , at 261.

127. Rohan, supra note 125, at 56; see also Note, Commercial Law and the American Volk: A Note on Llewellyn's German Sources for the Uniform Commercial Code, 97 Y ALE L.J. 156, 158 (1987) ("no scholar has been able to explain what Llewellyn thought 'immanent law' to be"). Llewellyn's concept of "immanent law", and its part in his conception of situation-sense, is discussed infra in the text accompanying notes 136-46.

128. Rohan, supra note 125 , at 71.

129. See, e.g., Feinman, supra note 124 , at $704-05$. It still may not offer quite as much as Llewellyn hoped. For although a legal decisionmaker may find an answer that feels both "right" and "inevitable" because it fits an existing ICM, there may be other available ICMs that would provide an answer that also has situation-sense. I discuss this phenomenon and the relative constraints imposed by experience and cultural knowledge in Transcendental Nonsense, supra note 10 , at $1182-98$. 
by experientialist theory; it lacks only an account of internal configuration. For Llewellyn, the concept of situation-sense was identified with, if not identical to, the process of categorization: In defining his concept, he stressed the distinction between the "facts of the individual case and the facts of the situation taken as a type."130 $\mathrm{He}$ understood situation-sense as a gestalt structure. ${ }^{131}$ Moreover, he recognized situation-sense as an extra-legal phenomenon fundamental to human rationality:

In any event - and this holds of the legal concept which is relevant just as it does of the life-situation - the sizing up of "the case" into some pattern is of the essence of getting to the case at all, and the shape it starts to take calls up familiar, more general patterns to fit it into or to piece it out or to set it against for comparison. This much, as we all know, is not a matter of method or desire, it comes close to being a matter of necessity, it is the way the normal human mind insists on working most of the time. 132

Llewellyn also understood this process as experientially based and largely image-dependent: One obtains access to situation-sense by "visualizing the hands-and-feet operations in the picture, seen as a going scheme, a working setup." 133 Llewellyn saw this knowledge as widely shared in the culture, ordinarily acquired through "such experience as, like driving a car or the party system or the Christmas season, comes to most Americans in the sheer process of survival to

130. K. LlewellyN, supra note 14, at 122.

131. See id. at 427 (" 'the' problem-situation extends as far as you are perfectly clear, in your own mind, that you have grasped the picture fully and completely ... and therefore know it to present a significantly single whole") (emphasis omitted). On the gestalt nature of ICMs, see G. LAKOFF, supra note 15, at 269-70, 302-03; Transcendental Nonsense, supra note 10, at 1152-53, 1178-79.

132. K. LlEWELLYN, supra note 14 , at 268 (emphasis added).

133. Id. at 261 . In this statement, Llewellyn notes both the experiential grounding and image-based nature of the cognitive process. Llewellyn had noted the experientially-based nature of reason much earlier:

We have discovered that rules alone, mere forms of words, are worthless. We have learned that the concrete instance, the heaping up of concrete instances, the present, vital memory of a multitude of concrete instances, is necessary in order to make any general proposition, be it rule of law or any other, mean anything at all.

K. Llewellyn, The Bramble Bush: ON OUR Law and Its Study 12 (1930).

Llewellyn probably took the "form of words" chestnut from Holmes, who used it inconsistently if not cynically. Compare Silverthorne Lumber Co. v. United States, 251 U.S. 385, 392 (1919) (government's argument for admitting illegally seized evidence "reduces the Fourth Amendment to a form of words") with Urofsky, The Brandeis-Frankfurter Conversations, 1985 SUP. CT. REv. 299, 334 (report by Brandeis that, in private, Holmes exulted "in the trick of working out what he calls 'a form of words' to express desired result"). For an indication that Holmes too recognized the image-based nature of linguistic meaning, see McBoyle v. United States, 283 U.S. 25, 26 (1931) (Holmes, J.) ("in everyday speech 'vehicle' calls up the picture of a thing moving on land."). For an excellent discussion of Holmes' jurisprudence as a model for pragmatist legal thinking that recognizes the social-situatedness of all thought, see Grey, supra note 99, at 798-810, 823-26. On the connection between Holmes' aestheticism and Llewellyn's, see id. at 861-62. 
maturity."134 In other cases, where the knowledge is specialized, situation-sense was to come from the judge "who already knows the little area or quirk of our culture which is the crux." 135 Otherwise, the advocate must educate the court by providing that knowledge in briefs and argument. ${ }^{136}$

For all its perspicacity, there is something about Llewellyn's own understanding of situation-sense that misled him to claim too much for it as a normative ideal. ${ }^{137}$ The classic statement of this claim provides a clue to the seeds of this misconception. In the best known description of situation-sense in The Common Law Tradition, Llewellyn quoted the nineteenth-century German scholar Levin Goldschmidt:

Every fact-pattern of common life . . . carries within itself its appropriate, natural rules, its right law. This is a natural law which ... is not a creature of mere reason, but rests on the solid foundation of what reason can recognize in the nature of man and of the life conditions of the time and place; it is thus not eternal nor changeless nor everywhere the same, but it is indwelling in the very circumstances of life. The highest task of law-giving consists in the uncovering and implementing of this immanent law. ${ }^{138}$

Critics of this passage have identified its objectivist leanings, focussing on concepts such as "immanent law," "natural rules," "right law" and such. And the critics are correct in identifying the purely normative dimension of this passage. Yet the passage equally proclaims its relativism, locating this hidden knowledge in "the life conditions of the time and place" and maintaining that "it is thus not eternal nor changeless nor everywhere the same."

It is not easy to harmonize these objectivist and relativist elements in Llewellyn's description of situation-sense, although some have tried. ${ }^{139}$ The answer, I believe, is not to try, but to acknowledge that

134. K. LLEWELLYN, supra note 14 , at 251.

135. Id.

136. Id. at 211-12.

137. As one commentator quipped, "he forsook realism for idealism." Rohan, supra note 125 , at 72 .

138. K. LlewellyN, supra note 14, at 122 (quoting L. Goldschmidt, Kritik des Entwurfs eines Handelsgesetzbuchs, 4 KRITISCHE ZEITSCHRIFT Für DIE GESAMMTE RECHTSWISSENSCHAFT 289 (1857)). This is the passage focussed on by Feinman, supra note 124, and Fischl, supra note 123, and referred to in Note, supra note 127. The student note reports that Llewellyn actually misidentified the source of the quote and locates the quote in a later work by Goldschmidt. Id. at 158 n.16. The note places Llewellyn's work in the context of the tradition of German Romantic "Natur der Sache" jurisprudence of the nineteenth century. Id. at 159-61.

139. The most sophisticated - and most nearly successful - attempt is Casebeer, supra note 106. Yet even he recognizes that: "There are passages seemingly impossible to reconcile." Id. at 697. Nevertheless, he argues that Llewellyn came close to discarding the fact/value distinction and to articulating a vision of "law as grounded in shared 'fact-value' conventions." Id. at 701 .

Twining suggests that Llewellyn's use of the Goldschmidt quote concerning "immanent law" 
Llewellyn was struggling to articulate an idea that was entirely novel. He had no paradigm with which to capture and no language with which to express both the dynamic, particular nature of experience and the value-laden process by which humans categorize that experience. ${ }^{140}$

The central precept of Llewellyn's realism, "see it fresh," was a reminder of the need to stay close to the actual and the particular and thus to avoid the chief pitfall of formalism, that of oversimplification ... whereas the other precept of realism, "see it whole," emphasized the need for a coherent frame of reference. Cautious striving towards the establishment of significant patterns, as embodied in the concept "situation sense," was Llewellyn's main formula for resolving the basic dilemma. ${ }^{141}$

But, despite his brilliant efforts, Llewellyn was a victim of this very basic dilemma. One of its manifestations was the distorted agglomeration of objectivist and relativist elements in a single normative formulation. Situation-sense was Llewellyn's effort from within the distorting conceptual apparatus of the subject/object dichotomy ${ }^{142}$ to capture the role of idealized cognitive models in legal analysis.

Llewellyn had no paradigm with which to describe the feel of objective justification that I called the "natural law response." In the absence of a formalized construct like an idealized cognitive model, he could not capture the automatic, unreflexive sense of validity that he described. ${ }^{143}$ Elsewhere in The Common Law Tradition, Llewellyn explicitly acknowledged that this perception was a function of cultural knowledge. He made clear, moreover, that the methodology of situation-sense was not a search for "natural law" as the Goldschmidt passage seemed to claim. But he lacked a way to talk about the quite structured feel of the phenomenon. "Immanent law .... indwelling in the very circumstances of life" was as close to the unconscious experience of cognitive structure as Llewellyn could come. Llewellyn was, therefore, vulnerable to the error of appearing to advocate reliance on naked social coherence as a sufficient normative ground for legal decision. And, from all appearances, he seems in fact to have succumbed to it.

was aberrational and a function of its similarity to a passage by Llewellyn's teacher, Corbin. "[H]is enthusiasm for the Goldschmidt passage might be explained in part by a feeling that he 'recognized' it without realizing why it seemed familiar." W. TwiNING, supra note 14, at 224.

140. Casebeer, supra note 106, at 697 ("one should expect such difficulty given a very different dominant tradition subverting the language in another direction").

141. W. TwINING, supra note 14 , at 369.

142. For a discussion that locates Llewellyn's work on the object side of this dichotomy, see Peller, supra note 124, at 1240-45, 1247-50.

143. See supra note 109. 
With the advantage of intellectual hindsight, however, it is a simple matter to expose as a social construction the feel of objective justification provided by this model of legal reasoning. In a recent article, I demonstrate how cultural ICMs structure a simple legal command like H.L.A. Hart's rule prohibiting vehicles in the park and more complex doctrinal areas like the first amendment. ${ }^{144}$ But there is nothing objective or foundational about this process of legal reasoning. An ICM is an experiential gestalt identified by a culture because it is a useful but not objective way to organize experience. Moreover, an ICM often entails socially contingent, normative accounts of experience as in the case of mother or in the invocation of the market metaphor to structure the concept of free speech. ${ }^{145}$ Both the ICMs used in ordinary interactions and the specifically legal ICMs used to structure doctrine are cultural artifacts encoding particular and contingent normative conceptions.

To say this is, in the end, not to criticize Llewellyn at all. For whether recognized as a cognitive function employing idealized cognitive models or denominated situation-sense, the process of legal reasoning remains a culturally-bound phenomenon. Llewellyn would plainly agree. ${ }^{146}$ The process is a creature of "the life conditions of the time and place; it is thus not eternal nor changeless nor everywhere the same," even if we do sometimes experience it as "indwelling in the very circumstances of life."147

\section{B. Legal Narrative and Social Constraint}

In saying that narrative is not a durable generator of legitimacy, I do not ignore its long association with law. The entire Jewish tradition of midrash, of interpretive storytelling, is a tradition of lawmaking. ${ }^{148}$ But, in my view, narrative plays only an intermediate role in this process. Consider, for example, the role of narrative in midrashic lawmaking.

In Genesis, the Bible tells the story of God appearing to Abraham as he was sitting at the door of his tent in the heat of the day. Accord-

144. Transcendental Nonsense, supra note 10 , at 1172-95.

145. In the case of mother, the cultural assumptions are those of a patriarchal, nuclear family. See supra note 29. In the case of the market metaphor for the first amendment, the assumptions relate to the presumed value of competition and laissez-faire economics. See supra note 31.

146. See K. LLEWELLYN, supra note 133, at 117 :

As to tools, law has borrowed copiously from the rest of culture: language, logic, writing; and for the subject matter of its thinking it borrows the whole stock of practices, standards, ethics that make up the social, economic and religious phases of society. What is dominant in society, then, is dominant in law.

147. K. LlewelLyN, supra note 14 , at 122.

148. Epstein, supra note 4, at $\mathrm{x}$-xiv. 
ing to the midrash, Abraham was recuperating from his circumcision, which is reported in the immediately preceding chapter of the Bible. ${ }^{149}$ The rabbis of the midrash interpreted this story as the source of the obligation of bikur cholim, of visiting the sick. ${ }^{150}$ In the next several verses, the Bible reports that Abraham ran to intercept three travellers (who later turn out to be angels), and invite them to dine.151 The rabbis of the midrash interpreted this story as a source of the legal obligation of hachnasot orchim, of entertaining strangers. ${ }^{152}$

One can understand this process of lawmaking through storytelling in two ways. In the first, the authority of this process is external to the story; it is hierarchical and inheres in the theological authority of the storyteller. In the second, the power of the narrator to create social meanings that will be understood as law is constrained by the available social understandings or mores. From this perspective, the trajectory of the story about Abraham and the three travellers is not from narrative directly to demand, but from practice to story to custom. The role of the rabbi is more that of midwife than mother; the role of the narrator is to concretize and communicate preexisting social practice in a way that will preserve and institutionalize it as a cultural norm.

Even so, this form of narrative is truncated, simple and highly formalized. We can see this same phenomenon in the case of an American cultural narrative like the "Horatio Alger story." Once an extensive oeuvre of over forty very specific novels and short stories written by the nineteenth-century author Horatio Alger, ${ }^{153}$ the concept of an "Horatio Alger story" has become a schematized "rags to riches" folk model that is a cultural template with which to measure a wide variety of social data from conversational stories ${ }^{154}$ to legal concepts like affirmative action. ${ }^{155}$ Once again, the trajectory is from the

149. Genesis 17:23-27.

150. Commentary of Rashi on Genesis 18:1 ("'And He [God] appeared to him': To visit the sick .... [I]t was the third day after his circumcision and the Holy One, Blessed Be He, came and asked after his welfare.") (citing BaBYlonian TALMUD, Tractate Baba Metzi'a 86b).

151. Genesis 18:1-4.

152. See 1 D. FREEDMAN \& M. Simon, supra note 4, at 414.

153. See, e.g., H. Alger, Bound to Rise (1873); H. Alger, Mark the Match Boy (1869); H. Alger, RAgGed Dick (1868); H. Alger, Strong AND SteAdy (1871).

154. Cf. L. Polanyi, supra note 97.

155. "Underlying much of the opposition to affirmative action is the myth that the American dream of success is based on merit, and that affirmative action undermines this system by ignoring merit in distributing rewards." Ellis, Victim-Specific Remedies: A Myopic Approach to Discrimination, 13 N.Y.U. REv. LAW \& Soc. ChANGE 575, 591 (1985); see also id. at 603 ("The American has thrived on the stories of individuals like Horatio Alger, whose examples offer the promise that success can be achieved through hard work.").

The "Horatio Alger" folk model is shared even by proponents of affirmative action. In 
social experience of pioneers and immigrants in the nineteenth century to specific narrative formulations and then to a stylized cultural model.

In a recent article, I characterize Robert Cover's notion that law is expressed as a "redemptive story" or "narrative" of a social struggle156 as corresponding to my explanation of legal reasoning as structured by means of ICMs grounded in social experience. ${ }^{157} \mathrm{I}$ argue that his notion of cases falling within the "central thrust" or "margin" of such "narratives" corresponds with my suggestion that legal doctrines are radial categories whose directive force is strongest at the core and weakest at the periphery. ${ }^{158}$ What makes Cover's conception funda-

United Steelworkers v. Weber, 443 U.S. 193 (1979), for example, the Court upheld a voluntary affirmative action plan in the face of a Title VII challenge. The majority opinion noted that "[i]t would be ironic indeed" if affirmative action were barred by "a law triggered by a Nation's concern over centuries of racial injustice and intended to improve the lot of those who had "been excluded from the American dream for so long." " 443 U.S. at 204 (quoting remarks of Senator Humphrey, 110 CoNG. REC. 6552 (1964)). In this view, affirmative action provides access to the American dream by serving as "an impetus to the process of dismantling the barriers, psychological or otherwise, erected by past practices." United States v. Paradise, 480 U.S. 149, 156 (1987) (Brennan, J.) (quoting NAACP v. Allen, 493 F.2d 614, 621 (5th Cir. 1974)). Thus, it is quite natural to find a proponent arguing that "[a]11 of the affirmative action programs considered by the Supreme Court in the last decade provided minorities with opportunities for self-support and self-advancement in the form of education, job training, business opportunities, or employment." Schnapper, Affirmative Action and the Legislative History of the Fourteenth Amendment, 71 VA. L. REV. 753, 796-97 (1985) (footnotes omitted).

As shaped by this dominant folk model, the desired end-goal of affirmative action is "a climate in which objective, neutral . . . criteria can successfully operate to select ... solely on the basis of . . merit." Paradise, 480 U.S. at 156 (Brennan, J.) (quoting Allen, 493 F.2d at 621). Thus, recent Supreme Court opinions upholding affirmative action plans have emphasized the degree of merit-based competition provided for by the plan under review. In Paradise, for example, the Court concluded that: "Finally, the basic limitation, that black troopers promoted must be qualified, remains. Qualified white candidates simply have to compete with qualified black candidates." 480 U.S. at 183 (emphasis added). And in Johnson v. Santa Clara Transp. Agency, 480 U.S. 616 (1987), the majority maintained that the affirmative action plan upheld the basic premise of the American dream. "Similarly, the Agency Plan requires women to compete with all other qualified applicants. No persons are automatically excluded from consideration; all are able to have their qualifications weighed against those of other applicants." 480 U.S. at 638 (emphasis in original). But see 480 U.S. at 674-75 (Scalia, J., dissenting) (arguing that the practice under the plan made meaningless the competition described by the majority). In contrast, the Court's recent decision in City of Richmond v. J.A. Croson, Co., 109 S. Ct. 706 (1989), struck down a racial set-aside in part because it was seen to conflict with the folk model of competition and individual achievement based on merit. See $109 \mathrm{~S}$. Ct. at 727 ("The dream of a Nation of equal citizens in a society where race is irrelevant to personal opportunity and achievement would be lost in a mosaic of shifting preferences . . . .").

156. Cover explains the decision in NLRB v. Catholic Bishops, 440 U.S. 490 (1979), in terms of the conflict between "the redemptive story of the [labor] struggle" and the "narratives of free exercise." Cover, supra note 10, at 63. Similarly, Cover explains the decision in Bob Jones Univ. v. United States, 461 U.S. 574 (1983), as a function of "the central redemptive narrative of the struggle for racial equality and for desegregation of the nation's schools." Cover, supra note 10, at 65 .

157. Transcendental Nonsense, supra note 10, at 1194 n.307. For an explanation of how ICMs structure legal reasoning, see $i d$. at 1182-85.

158. Id. at 1194 n.307. 
mentally different and richer than Ronald Dworkin's concept of law as a serial novel? Cover's narratives are the products of the embodied experiences of committed people. Dworkin's serial novel, on the other hand, is bound together only by abstractions of principle.

Nevertheless, I would suggest that Cover's "narratives" are themselves best understood not as prototypical stories of specific historical events. Rather, if they are to operate meaningfully as law for the group, they must make the transition from specific historical narratives to stylized cultural constructs that operate as idealized cognitive models. In this view of his work, the phenomenon of polynomia that Cover describes is not a function of the subjective power of the various narrators, but rather a nondeterminate product of the imaginative cognitive constructions of different social experiences.

Thus, to tell a story that will be both meaningful and compelling, the judge or other legal storyteller must make use of preexisting cultural knowledge in ways that will seem natural to those subject to the legal rule because already grounded in social experience and mediated by existing cultural models. We can think of the effective legal storyteller as one who "retails" cultural knowledge from the stock of practices produced by the culture at the "wholesale" level. 159 This view of lawmaking acknowledges that those who comprise the legal hierarchy do exercise substantial power in choosing legal rules or cultural norms; they may pick and choose from amongst a broad stock of practices those that will be institutionalized in legal rules.

This process nevertheless entails important cultural constraints on the legal storyteller. For, if the legal rule is not already grounded in social experience, the legal stories told by those who would make law will seem arbitrary and illegitimate. Unless grounded in these ways, legal stories run the risk that they will founder in the face of social discord, overt defiance, or failed communication. The statute books

159. See J. Deutsch, supra note 105, at 103 (describing Holmes' approach to lawmaking as working "as all good stories work, not by retailing the murky and confusing truth of how things are, but by confirming our felt certainties about how we know they should be."). Much the same process is at work when stories are used by those who wield political power to sell policies or candidates to the electorate. The power of the Willie Horton commercials used by those supporting George Bush's candidacy in the fall of 1988 lay precisely in the appeal to the kind of deepseated social stereotypes of antisocial black sexuality so eloquently depicted and critically examined by Eldridge Cleaver 20 years ago. E. CLEAVER, Soul ON ICE 13-15, 163-65, 178-90 (1968); see also J. WilliamSON, The CRUCiBle of RACE 116-17, 184-89 (1984) (describing the cultural construction by racial radicals in the late nineteenth-century South of the "problem" of black-on-white rape); Law, Homosexuality and the Social Meaning of Gender, 1988 WIS. L. REV. 187,233 n.220 ("The spectre of rape was the central justification of lynching.") (citing A. DAvIS, Women, Race \& Class 189-90 (1981); J. Hall, Revolt Against Chivalry: Jessie DANiEl Ames AND THE Women's CAMPAign Against LyNChing 112, 147 (1979)). The cognitive dimension of this phenomenon, which I denominate as the process of "affective" storytelling, is explored further in the next section. 
and case reports are littered with the evidence of just such failures. "Separate but equal" could not withstand the realities of segregation ${ }^{160}$ and the determination of its victims to have their story told. ${ }^{161}$ Enforcement does not keep up with illegal demand, whether the ban is that of prohibition in the 1920 s or the drug laws today. And the informer statutes, nineteenth-century laws that provide for private attorney general actions by any citizen with information about the alleged illegality, stand mute on the statute books in the face of the wide cultural acceptance of the individualist premises that lie behind the much-criticized standing doctrine. ${ }^{162}$

\section{Some Concluding Thoughts About the Transformative Power of NarRative}

I have suggested that narrative's communicative capacity is rooted in the way that the mind interprets, processes, and understands information. I have argued, nevertheless, that narrative has distinct limits as a tool of legitimation and that the narrative process is itself constrained by preexisting social understandings and practices. By this point in the argument, I trust that the reader will not mistake this description of cognitive constraints for an assertion of determinacy. There is nothing that requires any storyteller to tell a particular story or to tell it in a particular manner. We use stories all the time in an effort to persuade others to change their views or understandings. How does this work if our communicative success is limited by the prior experiences or understandings of the audience? And, if legal narratives are subject to social constraints, how can storytelling be used by the disempowered to effect social and legal change?

To explain this apparent conundrum, it is necessary to return to and stress three points about the cognitive sketch I provided in Part II.

160. Compare Plessy v. Ferguson, 163 U.S. 537, 551 (1896) (If "the assumption that the enforced separation of the two races stamps the colored with a badge of inferiority ... be so, it is ... solely because the colored race chooses to put that construction upon it.") with Brown v. Board of Educ., 347 U.S. 483, 494-95 (1954) ("To separate them ... solely because of their race generates a feeling of inferiority as to their status in the community that may affect their hearts and minds in a way unlikely ever to be undone. ... Separate educational facilities are inherently unequal.").

161. For the eloquent telling of this epic of bravery, resourcefulness, and commitment, see $R$. Kluger, Simple Justice (1975). Cf. P. Ricoeur, supra note 35, at 75 ("We tell stories because in the last analysis human lives need and merit being narrated. . . The whole history of suffering cries out for vengeance and calls for narrative.").

162. Standing, supra note 22, at 1406-09. In the revision of the Judicial Code in 1948, a 1792 statute (previously codified at 28 U.S.C. $\$ 823$ ) governing the award of costs in informers' actions was deleted as obsolete. Id. at 1408 n. 194 . In fact, there were then and are now still two informers' statutes on the books. 25 U.S.C. $\$ 201$ (1982) (actions to collect penalties for violations of certain Indian rights); 31 U.S.C. $\$ \S 3729-3730$ (Supp. 1989) (actions for fraud against the government). 
The first is that the cognitive process is fundamentally imaginative rather than mechanical. We understand and construct our world by imaginative connections through metaphor, metonymy, and the imaginative extension of idealized cognitive models. The second is that we share an ICM of narrative that depends upon and encodes a particular way of making sense of the world. The third is that, although idealized cognitive models are grounded in experience, they are not objective representations of that experience but idealized more-or-less characterizations. These three points are, jointly, the fulcra of the success of three types of prescriptive narratives: what I shall call affective, persuasive, and transformative storytelling.

When someone tells us a story, he or she invites us to enter a constructed world. Because we share basic cultural assumptions about how that world is constructed, we know that we are being asked to view that constructed world from a very particular point of view: that of the protagonist. And we usually do. We are able to because the ICM of narrative is structured by means of the source-path-goal schema and grounded in our common experience of journeys. We imagine ourselves as the protagonist and picture ourselves in the protagonist's shoes as we proceed from introduction to conclusion. Our very success in understanding the story is simultaneously the narrator's success in persuading us - at least temporarily - to imagine the world in a particular way.

This explains the first, affective way in which narrative persuades. The narrator invokes an existing storyline or ICM familiar to the audience. In this storyline, the narrator inserts a "nontraditional" protagonist. A black or woman works hard, obtains professional skills, and rises through the social strata only to be stopped by a discriminatory promotion decision that prefers a white male. Part of the power of this tale resides in its invocation of the cultural model of the "Horatio Aiger story." We believe that hard work pays off and that merit is rewarded even in the face of frequent lessons to the contrary. We believe it because, in our culture, we use this ICM to account for our experience; it is how we understand our world. The job of the advocate is to take the raw data of the client's story and reformulate it to conform to such an ICM and, therefore, to structure for the legal decisionmaker a sense of the situation that suggests only one specific outcome. ${ }^{163}$

163. See López, supra note 27. Perhaps the pithiest expression of this cognitive process is the admonition with which Herbert Wechsler regaled my first year class in criminal law. "In every murder case," he told us, "there are only two issues: Did the deceased deserve to die and, if so, was the defendant the person to do it?"

The example given in the text illustrates the problem I have with Clark Cunningham's other- 
We can confirm the power of this process by considering the occasions in which the narrator fails: those cases in which the audience is unpersuaded and refuses to accept the characterizations of events "imposed" by the narrator. This response may be especially strong even violent - if the audience is being asked to see protagonists and villains that do not fit its concepts of identity and order. ${ }^{164}$ The white male judge who unconsciously harbors stereotypes about blacks and women may react with disbelief because he cannot accept the narrator's characterization of protagonist and villain. ${ }^{65}$ The reaction will

wise thougtful account and explanation of his lawyering experiences in terms of the metaphor of lawyering as translation. Cunningham, $A$ Tale of Two Clients: Thinking about Law as Language, 87 MICH. L. REV. 2459 (1989). Cunningham's metaphor is valid in certain circumstances. But it seems to assume a kind of legal ethnocentricity that sees legal "language" as separate and apart from lay "language." In fact, however, legal language is largely continuous with lay language in at least two ways. First, and most obviously, legal language makes use of many of the same terms and, thus, underlying understandings as ordinary English. We saw an example of this in the notion of "contract." See supra text accompanying notes 110, 144-46. Second, as illustrated in the case of the "Horatio Alger" folk model, lawyers, judges, and lay persons are all situated members of the same general culture. Accordingly, they cognize their world, are affected by, and act in accordance with the same set of powerful cultural constructs. See supra text accompanying notes 159-62. Thus, in many such cases, the role of the lawyer is not to translate so much as to facilitate the client's own version of his or her story.

This is not to say, however, that there are no specifically legal ICMs; law can be conceptualized as a dialect or subculture. In cases in which the legal and lay subcultures confict, Cunningham's model is a sensitive and useful way to conceptualized the problems of advocacy.

164. Seymour Chatman's essay about film narrative provides an example of this process. In his paper, Chatman describes how Jean Renoir's film adaptation manages effectively to capture and translate Guy de Maupassant's short story Une Partie de Campagne. De Maupassant describes Henriette: "She was a pretty girl of about eighteen; one of those women who suddenly excite your desire...." Chatman, supra note 47, at 126. Chatman explains how Renoir conveys this idea by using the camera to show the point of view of several men of different ages and social situations as they are all drawn to admire Henriette on a swing. Id. at 126-35. Chatman reports that, at this point of his paper, several conference participants objected to the sexism of the description. "The objection seemed to be not about the voyeurism itself but about the willingness of the members of an audience to go along with it." Id. at 135 n.4. Chatman defends his scholarly effort:

The kind of identification that I was discussing is . . . purely aesthetic. A reader must obviously be able to participate imaginatively in a character's set of mind, even if that character is a nineteenth-century lecher. ... Imaginative participation in the point of view of fictional characters ... in no way implies moral endorsement. It is simply the way we make sense ... out of unusual or even downright alien viewpoints.

Id. at 135 n.4. What Chatman misses, of course, is that this process of imaginative participation is the very gist of the criticism: The perniciousness of this particular narrative is that, to understand the story, the audience is being asked to - and does - go along with the act of voyeurism. The complaint is precisely moral: that the audience becomes an accomplice in the narrator's sexism.

165. [T] here are psychic rewards in self-flattering generalizations. ... [I]t's a rare person who isn't delighted to hear and prone to accept comparative characterizations of ethnic or other groups that suggest the relative superiority of those groups to which he belongs. ...

... By seizing upon the positive myths about the groups to which they belong and the negative myths about those to which they don't, or for that matter the realities respecting some or most members of the two classes, [lawmakers], like the rest of us, are likely to assume too readily that not many of "them" will be unfairly deprived, nor many of "us" unfairly benefitted ....

J. ELY, DEMOCRACY AND DISTRUST 158-59 (1980); see also Lawrence, supra note 57, at 338-39 ("[O]ur culture often supports and rewards individuals for making hostile misjudgments that 
be: "that's a good story, Counselor, but what about the fact that . ..."

If the judge is the legal storyteller and the losing victim of discrimination the audience, the roles will be reversed. The opinion will invoke a stylized cultural story presenting, for example, the picture of beleaguered management caught in the vise of "unqualified" minority applicants who cannot live with their disappointment and "bleedingheart" civil rights laws left over from the "misguided" sixties. In that case, the victim will not recognize his or her experience in the tale told by the narrator. The reaction will be that "the judge is just exercising raw [narrative] power."

I have called this use of narrative merely affective both because of the temporary nature of the persuasion and the degree to which it appears dependent upon the audience's predispositions and commitments. How does the advocate or storyteller actually persuade someone to change his or her position? The answer lies in the epistemic role of experience. The advocate's repertoire is not limited to the offer of alternative ICMs, which the decisionmaker may accept or reject on the basis of its precommitments. Rather, the advocate can adopt an educative strategy designed to bring the court to see a situation in a substantially new way.

The key to such a strategy is the understanding that although categories are socially constructed, it does not follow that they are arbitrary or that, in any given case, they can be anything. Rather, categories work or don't work, fit or don't fit, given the available experience and information they are being used to organize. Thus, the advocate can offer concrete facts and experiences that make the court's ICM inapplicable and another ICM more obviously so. Knowing that the decisionmaker may approach a legal problem in one way, the advocate can tell a story that simply does not fit with the tribunal's sense of the situation. The sheer force of detail can be used to press the tribunal to rethink the situation, to recategorize a case as an exception to its dominant paradigm and an instance of another ICM. This is the proverbial "smoking gun": that key fact which is inconsistent with one view of the situation and, at the same time, a prototype of another ICM. The advocate can construct a story that is persuasive because it provides a more coherent version of the facts presented; it is persuasive precisely because of its appeal to the basic cognitive impulse to organize and make meaning in experience.

Llewellyn provides two salient examples of this process in his de-

exaggerate the differences between themselves and members of a racial out-group. ... In ambiguous social situations, it will always be easier to find evidence supporting an individual's assumed group characteristics than to find contradictory evidence."). 
scription of situation-sense in operation. In the first, the New York courts had held that oral contracts to transfer credit were subject to the statute of frauds and therefore unenforceable. He describes the successful argument of counsel in the next case:

I wish I might have had that oral argument to make: the almost startling picture of a major international bank's foreign exchange expert at work in an unstable, still free, market, with four assistants and ten or more telephones all busy as offers in the tens or hundreds of thousands are received and held open during a lightninglike shopping around, or are made and held "firm for three minutes" or are "closed" by word of mouth in closings that have to mean binding obligations. It was such a picture of the type-situation which knocked out the Statute of Frauds .... which the court does not quote.... [W] hat we have is advocacy informing the court ... about wise choice of concept and consequent rule ... informing so persuasively that the court turns its back on the plain text of a statute to strong-arm an exception . . . . ${ }^{166}$

In this case, the advocate tells a story of the actual "hands-and-feet techniques of commercial bank operation" 167 that does not permit the sensible application of a category constructed for other circumstances.

The second example is the "managed series of educational cases, judiciously selected - even at times arranged - to bring a court or the courts along by gentle stages of understanding." 168 A now-familiar example is the litigation strategy that led to Brown. ${ }^{169}$ In this process, the advocates slowly expose the courts to ever greater accretions of experience that do not fit the reigning legal paradigm until, ultimately, the courts are led to reformulate the available models to fit the experiences they had previously ignored. ${ }^{170}$ Here, we have crossed the

166. K. LlEWELLYN, supra note 14, at 211-12 (footnotes omitted) (describing Equitable Trust Co. v. Keene, 232 N.Y. 290, 133 N.E. 894 (1921)).

167. Id. at 212 .

168. Id. at 262.

169. Brown v. Board of Educ., 347 U.S. 483 (1954). See K. LLEWELLYN, supra note 14, at 262-63. Brown was the culmination of a conscious process of litigation strategy that began in the early thirties. The heroes and architects of this triumph of advocacy include not just Thurgood Marshall, but also Charles H. Houston, William H. Hastie, and Nathan Margold. See, e.g., R. KLUGER, supra note 161, at 132-36, 155-65, 186-94, 202-06; M. TUSHNET, ThE NAACP'S Legal Strategy Against Segregated Education 21-48 (1987).

170. Cf. Cornell, Institutionalization of Meaning, Recollective Imagination, and the Potential for Transformative Legal Interpretation, 136 U. PA. L. REv. 1135, 1170 (1988) ("The irreducible exteriority, or the inevitable residue of materiality in history, does not stand completely outside of interpretation. Yet, that being said, there is a limit implicit in the finitude of human life that cannot, with a sweep of the hand, be interpreted away."). It is at this point that I disagree with the strong version of Fish's critique of Dworkin, see Fish, supra note 113. Consider the midrash about Abraham and the idols and hypothesize a serial author who picks up the story immediately after the confrontation between Terach and his son over the broken idols. Is this author exactly as free as the first? The first could have written any kind of story, even any kind of story of faith. But the second must make something of Abraham's iconoclasm; it is too powerful an image not to be accounted for. It may yet mean many things; but there are some things it cannot mean. Thus, for example, it is difficult to see how a serial author could turn Abraham's act into an 
divide from the persuasive to the transformative. At this point, narrative is used to play a crucial role in reconstructing the outcomes of legal and social debate.

In my recent Transcendental Nonsense, Metaphoric Reasoning, and the Cognitive Stakes for Law, I argue that rights must be grounded in the experiences of the beneficiaries if they are to be meaningful. ${ }^{171}$ How is this possible when "experience" is different for different people and, by definition, the lawmakers have not shared the experience of the disempowered? Again, the answer lies in the cognitive role of experience and imagination. The transformative potential of narrative inheres in the cognitive power of concrete imagery and the empathetic potential of the imagination.

One reason for the transformative potential of narrative is its capacity to present forceful images and relatively concrete experiences in a comprehensible manner. There is a "basic level" of cognitive interaction with the environment that conforms to human perceptual abilities relative to observable attributes, motor movements, and similarity in shape. ${ }^{172}$ Thus, to take the simplest example, the neurophysiological process of color perception is such that the names of some hues are more easily learned and remembered than others. ${ }^{173}$ The grounding of all human cognition in experience means that there is a greater cognitive "clout" to images from lived experience as compared to propositional formulations that attempt to "literalize" their meaning. The dramatic image of Abraham smashing the idols, for example, has a

affirmation of the familial status quo. The difficulty inheres not in anything intrinsic to the story, but rather in the grounded manner in which we make meaning. This disagreement, however, does not vitiate the power of Fish's critique of Dworkin. For the trajectory and meaning of the story is still open to reconstruction by the serial author. Thus, while there are constraints on what the act might mean, there is no constraint on the next installment that determines whether the story will become one of reconciliation or remain one of rebellion.

171. Transcendental Nonsense, supra note 10, at 1224-34.

172. The concept of a "basic level" derives from the experimental work of Eleanor Rosch in the field of categorization. Rosch, Principles of Categorization, in COGNITION AND CATEGORIZATION 27 (E. Rosch \& B. Lloyd eds. 1978). Rosch posits that humans form "categories . . . to maximize the information-rich cluster of attributes in the environment," and that categorization at this level shows the greatest degree of stimulus commonality within the category and of stimulus discontinuity between related categories. Id. at 37 .

173. There is a substantial body of recent empirical work that documents the cross-cultural nature of prototype effects in the perception of the color spectrum regardless of language and cultural differences. Transcendental Nonsense, supra note 10, at 1137-40. Eleanor Rosch found that when the children between three and four years old were asked to "show a color to the experimenter," "focal" colors were more frequently selected than were "nonfocal" colors; "focal" colors were also more accurately matched and more frequently chosen to represent the color name. Rosch \& Heider, "Focal" Color Areas and the Development of Color Names, 4 DEv. Psychology 447 (1971); see also Rosch \& Heider, Universals in Color Naming and Memory, 93 J. EXPERIMENTAL PSYC. 10, 19 (1972); Rosch, Heider \& Olivier, The Structure of the Color Space in Naming and Memory for Two Languages, 3 Cognitive Psychology 337 (1972); Rosch, Natural Categories, 4 Cognitive Psychology 328, 331 (1973). 
communicative power that is unmatched by the "equivalent" propositional statement "Abraham rejected as empty his father's religious practices and authority." 174

Transformative argument is possible because the advocate can use narrative to invite the audience into the world of the rights-holder (or rights-seeker). That world will be constructed in part of models and metaphors already shared with the audience. ${ }^{175}$ But within this constructed story-world, there will be depicted concrete experiences that are unfamiliar or unknown to the audience. Through the process of projection that makes possible narrative understanding, the audience will imagine itself confronted by these experiences; it will be challenged to make sense of them through its own past experiences in order to understand the story-events as a coherent story-experience of its own. ${ }^{176}$ The concrete power of the imagery with which the reader can be confronted - Abraham smashing the idols, the boy drawing the targets around the arrows - can be used directly to engage the audience in the cognitive process by which it regularly makes meaning in its day-to-day world. Because the cognitive process is basically imaginative, the process of making sense of the projected experience of the story will be mimetic of the process by which humans always make meaning. The audience "lives" the story-experience, and is brought personally to engage in the process of constructing meaning out of another's experience. ${ }^{177}$ Through this process, the audience can achieve a measure of understanding and empathy. Transformative communication is possible, but there are no guarantees.

Let me concretize this with a specific example. Not long ago, I watched a rerun of one of my favorite episodes of the situation-comedy "Taxi." Louie (Danny DeVito), who is the dispatcher, is caught peeping at Elaine (Marilu Henner), one of the cab drivers, while she is

174. Similarly, in discussing the meaning of the blindfold worn by Justicia, Cover observes that " $[t]$ he richness of the concreteness of our icon lies in its incapacity to be reduced 'merely' to an idea like impartiality." R. Cover, O. Fiss \& J. Resnik, Procedure 1231 (1988).

175. Because we are essentially similar subjects interacting with our environments in terms of the same processes, there is quite a lot of meaning that is shared. We also share large amounts of mediated, social experience such as the completely value-laden, socially constructed experiences that make up the meaning of the ICM of mother. See supra note 29. We use these models, metaphors, image-schemata, and other basic experiences that are shared to understand other things that are not. In this way, nonshared meaning is commensurable and thus potentially communicable even to others who have not had the same experiences.

176. Cf. Minow, supra note 29, at $89-90$ "'I petition all judges to open up to the chance that someone may move them - the experience will not tell them what to do, but it may give them a way outside of the routinized categories to forge new approaches to the problem at hand.") (footnote omitted).

177. See id. at 80 ("Putting ourselves in the place of those who look different can push us to challenge our ignorance and fears and investigate our usual categories for making sense of the world."). 
dressing in the ladies' room. Elaine threatens a discrimination suit for sexual harassment and succeeds in getting Louie fired. Louie then shows up at Elaine's apartment to beg her forgiveness and engage her help in getting his job back.

Elaine tells him that she will only forgive him and help get his job back if he comes to understand why what he did is wrong, and that he can only do that if he understands how he made her feel. Anyone who knows the show understands that this is especially difficult because, aside from the ordinary gulf between the experiences and perceptions of men and women, the Louie character is the world's least empathetic, most crude and cynical human. In fact, Elaine is fairly confident that she will not have to make good on her offer; "There is no way that you can understand."

Louie quickly comes up with the obvious: "I know, I know, because I made you feel like an object."178 (In an aside, he says: "Boy, am I glad I watched that Donahue. Broads love that stuff.") After a few more tries, Elaine begins to take pity at Louie's desperation and appeals to his experience: "Hasn't something ever happened to you where everybody was looking at you and that made you feel terrible?" Louie, of course, is unusually short. He describes what it is like, once a year, to go to the boys' section of the department store to buy a new suit. He tells the story, describing the mortification he feels as the mothers shush their sons and then turn away when he looks in their direction. "Is that how I made you feel?"

This story illustrates the role that experience and projection play in communication and intersubjective meaning. Neither Louie nor any other man can understand directly the degradation a woman feels when she is spied on. If someone had peeked in on Louie when he was dressing, the "events" would have been the same in one sense but the "experience" would have been entirely different. Nevertheless, Louie is able to understand Elaine's feelings by means of his own experience. Even though both of their feelings are mediated differently - hers by her previous experience as a woman, his by the experience of his stature - communication and shared meaning are nevertheless attainable. This meaning will not be determinate - that is, Louie's understanding of what Elaine felt will not be isomorphic with hers. ${ }^{179}$ Nevertheless, the imaginative processes of cognition enable Louie to

178. Taxi: Louie Goes Too Far (ABC television broadcast, December 17, 1981).

This formulation is based on an object metaphor and is intelligible precisely because we know what an object is with very little conscious mediation and because we are capable of metaphoric projection - that is, understanding Louie's treatment of Elaine by means of one's treatment of a literal object for its instrumental value only.

179. To underline the imperfection of this process of communication, the episode ends with a 
achieve a degree of empathy and to understand Elaine's experience by means of his own. A moment of "intersubjective zap" has been achieved. ${ }^{180}$

This is what I mean when I suggest in my Transcendental Nonsense article that rights can be made meaningful if grounded in the experience of people. ${ }^{181}$ First, I mean that it is critically important for women and blacks and other minorities to tell these stories. ${ }^{182}$ Second, I mean that we need to make the effort to use the tools of comprehension and communication to understand what that experience is like: what it feels like to be discriminated against; what it feels like to be taken for granted, reduced to an object, and abused. This kind of empathetic understanding is difficult to achieve; it can be done only when we understand that it is human experience we are trying to comprehend, and not some objective description of "events" in the world. Third, I am arguing that we can - with work - accomplish that understanding. I think so because I understand meaning as arising from basic interactions with a shared environment and a shared (but not identical) social reality. Moreover, I understand meaning as an imaginative process. For most of us who share substantially the same culture, the same ICMs mediate our experience and are available for communication. Beyond that, narratives that express particular, individual experiences can be communicated by means of appeals to commonalities, by metaphor, and by storytelling - specific, imaginative constructions that are expressed in the concrete realities of our everyday experiences.

To paraphrase Nelson Goodman: In narrative, experience moonlights as intersubjective meaning. ${ }^{183}$

sitcom twist: while Louie and Elaine embrace to celebrate their moment of connection, Louie reaches down and squeezes Elaine's buttocks.

180. The term "intersubjective zap" is Duncan Kennedy's. Gabel \& Kennedy, Roll Over Beethoven, 36 STAN. L. REV. 1, 4 (1984).

181. Transcendental Nonsense, supra note 10, at 1228-34. It should be clear from even a cursory reading of my Transcendental Nonsense that I advocate no "aestheticized" self-transformation through imagination and narrative. Rather, as I say there: "To make meaning, one must do meaning." Id. at 1231. With Cover, I believe that meaning is made through committed action - "in the medium of blood." Id. (quoting Cover, supra note 10, at 47-48).

182. West, Jurisprudence and Gender, 55 U. CHI. L. REV. 1, 65 (1988).

183. Goodman, Metaphor as Moonlighting, in ON METAPHOR, supra note 15, at 180. 